\title{
Air pollution, avoidance behaviour and children's respiratory health: Evidence from England
}

\author{
Katharina Janke \\ University of Bristol \\ 2 Priory Road \\ Bristol \\ BS8 1TX \\ United Kingdom \\ Katharina.Janke@bristol.ac.uk
}

August 22, 2014

\begin{abstract}
Despite progress in air pollution control, concerns remain over the health impact of poor air quality. Governments increasingly issue air quality information to enable vulnerable groups to avoid exposure. Avoidance behaviour potentially biases estimates of the health effects of air pollutants. But avoidance behaviour imposes a cost on individuals and therefore may not be taken in all circumstances. This paper exploits panel data at the English local authority level to estimate the relationship between children's daily hospital emergency admissions for respiratory diseases and common air pollutants, while allowing for avoidance behaviour in response to air pollution warnings. A $1 \%$ increase in nitrogen dioxide or ozone concentrations increases hospital admissions by $0.1 \%$. For the subset of asthma admissions - where avoidance is less costly - there is evidence of avoidance behaviour. Ignoring avoidance behaviour, however, does not result in statistically significant underestimation of the health effect of air pollution.
\end{abstract}

KEY WORDS: air pollution, child health, asthma, avoidance behaviour, panel analysis JEL I12, I18, Q53, Q58 


\section{Introduction}

Although air quality in the UK has improved greatly since the Great Smog of London in 1952, a recent report by the House of Commons Environmental Audit Committee (2010) concluded that "poor air quality probably causes more mortality and morbidity than passive smoking, road traffic accidents or obesity". Children are especially vulnerable to air pollution exposure because of their developing lungs and immature immune systems and because they spend more time outdoors (World Health Organization - European Centre for Environment and Health 2005) and respiratory disease is one of the leading causes of hospitalisation of children. This paper examines the effect of air pollution on hospital emergency admissions for respiratory diseases in children.

The UK government, in common with other governments, provides daily air pollution forecasts that are freely available via the internet, a Freephone telephone service and Teletext as well as with the weather forecast in newspapers, on TV and radio. We therefore expect individuals susceptible to air pollution, such as asthmatics, to avoid exposure to raised levels of air pollution. If avoidance behaviour exists, estimates of the health effects of air pollution will be biased. The reason is that the standard approach in the literature is to approximate air pollution exposure by measurements taken at fixed-site outdoor monitors. Therefore, avoidance behaviour could cause mismeasurement of air pollution exposure. For example, if people stay indoors on a high air pollution day and consequently actual exposure is very low, we might observe a reduction in hospital admissions, which results in underestimation of the effect of air pollution on hospital admissions. On the other hand, avoidance behaviour, such as staying indoors, imposes a cost on individuals that might exceed the perceived gains. This paper investigates whether ignoring avoidance behaviour leads to bias in the estimates of the negative effects of pollution on children's health.

I exploit a large panel data set in which the unit of analysis is the primary unit of local government in the United Kingdom (known as a local authority). For these units, I have compiled daily data on hospital emergency admissions of children aged 5 to 19 years, two criteria pollutants - nitrogen dioxide and ozone - and air pollution warnings, the latter to measure avoidance behaviour. The data cover 89 local authorities in England for 2003 to 2007, containing $45 \%$ of the 9.5 million children aged 5 to 19 in England. My research design exploits daily variations in air pollution levels, which are mainly caused by random changes in atmospheric conditions and pollutant emissions. The high frequency of my data and the large panel dimension mean I can control for national year-week effects, which capture trends, seasonal effects and epidemics that are national in scope, and local authority-yearquarter effects to control for changes in hospital practices or economic activity, which might be correlated with pollution levels, at the local level. I also control for daily variations in weather and smog conditions and allow for delayed effects of air pollution exposure. Given this rich set of controls, the deviations in pollutant concentrations are likely to be exogenous to omitted factors and my estimation design recovers the causal effects of the pollutants. 
I complement this national study with a study of visits to an outdoor attraction (a zoo) by two groups of parents and children. For one of these groups, members, avoidance is less costly, allowing me to test whether avoidance behaviour is more likely when the cost is low.

My findings suggest that both nitrogen dioxide and ozone at the relatively low levels experienced in England lead to respiratory hospital admissions in children. A $10 \%$ increase in nitrogen dioxide or ozone increases the rate of hospital emergency admissions for all respiratory diseases and symptoms in children aged 5 to 19 years by around 1\%. I find evidence of avoidance behaviour for the subset of hospital admissions for asthma. For asthmatics the cost of avoidance is low, because a sufficient response to air pollution warnings is adjusting the dose of their reliever medicine and making sure they carry their inhaler. The direct effect of an air pollution warning is an $8 \%$ reduction in asthma admissions. Ignoring avoidance behaviour, however, does not result in statistically significant underestimation of the effects of nitrogen dioxide and ozone.

The closest antecedent to my paper is Neidell (2009), who investigates the effect of ozone on hospital admissions for asthma in Southern California in the 1990s. Neidell exploits daily variation in air pollution within 22 source receptor areas in a fixed effects regression with year-month dummies. He controls for avoidance behaviour by including a smog alert dummy variable in his specification and finds evidence suggestive of avoidance behaviour in response to smog alerts. He also examines data on visits to outdoor attractions, for example Los Angeles Zoo, and finds that attendance is lower on days when smog alerts are announced. Attendance at the zoo drops more sharply for members, for whom as local residents the cost of avoidance are lower, and for children and the elderly, for whom the benefits of avoidance are higher.

In addition to studying a different country and time period, my study setting is very different from Southern California, where - due to a long history of high ozone levels and smog - people are likely to be aware of the health effects of air pollution. In England, ozone levels rarely exceed limit values and there is little awareness of the implications of poor air quality (Defra 2007). I also go beyond Neidell's research in several key aspects. First, I show that avoidance behaviour is different across subsets of respiratory disease. I compare the effect of air pollution warnings on hospital admissions for asthma, where the costs of avoidance are low, to admissions for acute respiratory infections, where the costs of avoidance are higher. I complement this analysis with a comparison of the behaviour of two groups with different avoidance costs by analysing the response of members and day visitors to Bristol Zoo to air pollution warnings. Pollution warnings reduce visits by members, who tend to be local residents, but have no effect on the number of day visitors, for whom reorganising a zoo visit or obtaining information about local air quality is probably more costly. Second, I implement a stronger identification strategy. My specification allows unobserved differences between areas to evolve at a quarterly rate by including year-quarter fixed effects. Additionally, I include year-week rather than year-month dummies to control for seasonal cycles and influenza 
epidemics. I present a robustness test that replaces the year-quarter fixed effects with yearmonth fixed effects. Third, my sample is large and covers approximately $45 \%$ of the total population of 50 million in diverse locations, ranging from old mining and steel towns in the north to affluent areas in London and the South East. The scope of Neidell's study is limited to 22 of the 38 source receptor areas within the South Coast Air Quality Management District, whose total area is about $28,000 \mathrm{~km}^{2}$ compared to $130,000 \mathrm{~km}^{2}$ of England.

This paper is also connected to a large epidemiological literature. I discuss the epidemiological approach and the related economics literature in the next section. I then present the details of my estimation strategy in Section 3. Section 4 provides an overview of the extensive data I have brought together from various administrative sources. Main results and a simple cost-benefit analysis of the air pollution forecast are in Section 5. Section 6 shows the robustness of the results to specification changes, presents a falsification test that uses digestive diseases as a placebo outcome and extends the analysis by examining interaction effects and spatial heterogeneity. Section 7 provides direct evidence of avoidance behaviour in visitor data from Bristol Zoo. The discussion in Section 8 compares the size of my estimates to earlier studies before concluding the paper.

\section{Related literature}

Epidemiologists studying the relationship between air pollution and hospital admissions traditionally examine time series for a single city. For example, de Leon et al. (1996) analyse data for London in 1987 to 1992 and Atkinson et al. (1999) extend this analysis for the period 1992 to 1994. Anderson et al. (2001) conduct a study in the West Midlands conurbation in England for the period 1994 to 1996. Fusco et al. (2001) report an association between air pollutants and respiratory hospital admissions in Rome, Italy, for the period 1995 to 1997. Examples of non-European studies are Burnett et al. (1994), who investigate admissions to Ontario hospitals, and Petroeschevsky et al. (2001), who analyse data for Brisbane, Australia. The less common multi-city studies such as the "Air Pollution and Health: A European Approach" project (APHEA) estimate pollutant effects for each city with city-specific models. In a second stage, they derive pooled regression coefficients. Sunyer et al. (1997) investigate the relationship between air pollution and children's asthma admissions in Helsinki, London and Paris. They compute a combined estimate across cities by taking the weighted average of the city-specific coefficients using inverse variance weights.

These studies focus on achieving a good statistical fit. For example, they control for trends and seasonal cycles through sinusoidal terms or smooth functions of calendar time. They include smooth functions of meteorological variables where the degrees of freedom are chosen to minimise an information criterion. Most estimate single-pollutant models, which might cause omitted variable bias. They choose the most significant pollutant lag (see, for example, the APHEA protocol (Katsouyanni et al. 1996)), which amplifies the problems 
associated with pre-test estimation. None of the epidemiological studies model behavioural changes in response to air quality information.

The aforementioned paper by Neidell (2009) is one example of the approaches taken by economists in an attempt to overcome the endogeneity issues of many epidemiological studies. The seminal paper by Chay and Greenstone (2003) examines infant mortality at the county level using the differential reduction in pollution levels induced by the 1981-82 recession to identify the effect of air pollution. Exploiting local variation in regulation intensity in pursuit of compliance with the 1970 Clean Air Act, Chay et al. (2003) investigate the relationship between air pollution and adult mortality. Another strand of the literature uses individual level data abstracted from birth and death certificates to investigate air pollution effects on infant mortality (Currie and Neidell 2005, Currie et al. 2009). Knittel et al. (2011) additionally instrument for pollution exposure using road traffic measures. Studies of air pollution effects on morbidity include Lleras-Muney (2010), who exploits compulsory relocations in the military to estimate the effects of air pollution on children's respiratory hospitalisations, as well as Moretti and Neidell (2011) and Schlenker and Walker (2011), who examine hospitalisation rates in California using instrumental variable approaches. All of these studies use American data. In one of the few non-US studies, Coneus and Spiess (2012) use survey data from the German Socio-Economic Panel on infant and toddler health outcomes, which allow them to control for a wide range of confounders. The small sample size, however, limits the power of their study.

Most research into avoidance of air pollution exposure is based on individuals' responses to survey questions about their behaviour with respect to air quality information. For example, Bresnahan et al. (1997) surveyed 230 Los Angeles residents during 1985 to 1986, finding that people report making behavioural changes to avoid smoggy conditions. Skov et al. (1991) conducted a questionnaire survey in Copenhagen, Denmark, asking around 1,000 respondents about their response to air quality information. They find that people with pre-existing health conditions are more likely to report avoiding outdoor activity in response to a pollution alert. Bickerstaff and Walker (1999) conducted a questionnaire survey followed by in-depth interviews in Birmingham, UK. According to the survey a majority of people had taken some protective action during pollution episodes. During the interviews, however, it emerged that a number of actions had been prompted by other factors, such as pollen or high temperature, rather than air pollution alone. Most relevant to my study are the paper by Neidell (2009) already discussed in the introduction - and the paper by McDermott et al. (2006). McDermott et al. (2006) conducted a survey of 240 parents in Salt Lake City, Utah. Half of the survey respondents had children who suffer from asthma. They find that parents of asthmatic children are more likely to report restricting children's outdoor activity when air pollution levels are high. However, when asked about the number of days per year they restrict children's activities, $90 \%$ of parents reported less than 11 days. Since air pollution alerts were issued for around 30 days per year, the authors conclude that the majority of parents respond 
to only a small percentage of alerts. Because of their reliance on self-reports, these studies may be affected by recall bias or framing. The only exception is Mansfield et al. (2006), who report results from a study using activity diary data for children, which found that children with asthma reduce time spent outdoors by 30 minutes on days for which air pollution alerts have been issued.

\section{Methods}

My unit of analysis is the local authority, the primary unit of local government in the UK. I study the association between the daily average air pollution exposure of a local authority's population and the daily hospital emergency admissions rate of that population. My dataset contains daily observations for a period of up to 5 years for the 89 local authorities mapped as shaded areas in Figure 1. The sample authorities represent $45 \%$ of England's population. ${ }^{1}$ I discuss the sample selection criteria below, but the basic idea is to include all English local authorities with an area of less than $600 \mathrm{~km}^{2}$ and a total population of at least 150,000 for which sufficient data are available instead of only one city (or 20 large European cities) to minimise city selection bias. The resulting larger number of observations allows the unit of analysis to be smaller, reducing measurement error in the air pollution variables without loss of statistical power. For example, epidemiological studies assign one air pollution measure to the whole London conurbation, whereas I split it into its 32 boroughs.

\subsection{Basic equation}

I estimate the following panel regression:

$$
\begin{aligned}
\text { admissions }_{a, r, t}= & \sum_{i=0}^{4}\left[\beta_{i}^{N O_{2}} N O_{2} a, t-i+\beta_{i}^{O_{3}} O_{3 a, t-i}+\gamma_{i} \text { warning }_{r, t-i}\right]+ \\
& \sum_{i=0}^{4}\left[\boldsymbol{M}_{a, t-i}^{\prime} \boldsymbol{\delta}_{i}\right]+\boldsymbol{X}_{t}^{\prime} \boldsymbol{\lambda}+\sigma_{a, q(t), y(t)}+\tau_{w(t), y(t)}+\varepsilon_{a, r, t}
\end{aligned}
$$

The dependent variable, admission $s_{a, r, t}$, is the number of hospital emergency admissions per 100,000 population in local authority $a$ in urban area or region $r$ on day $t$. The explanatory variables of interest are $\mathrm{NO}_{2} a, t-i$ and $\mathrm{O}_{3} a, t-i$, the contemporaneous value and four lags of the air pollutants nitrogen dioxide $\left(\mathrm{NO}_{2}\right)$ and ozone $\left(\mathrm{O}_{3}\right)$ in local authority $a$, and the dummy variable warning $_{r, t-i}$, which indicates an air pollution warning in urban area or region $r$ on day $t-i$. Control variables are $\boldsymbol{M}_{a, t-i}$, a vector of meteorological variables, and $\boldsymbol{X}_{t}$, a vector of dummy variables which I discuss below. $\sigma_{a, q(t), y(t)}$ is a local authority-year-quarter fixed effect, $\tau_{w(t), y(t)}$ a year-week effect and $\varepsilon_{a, r, t}$ the error term.

\footnotetext{
${ }^{1}$ The total population in the local authorities in the estimation sample (all ages) is around 23 million, the English population around 51 million.
} 


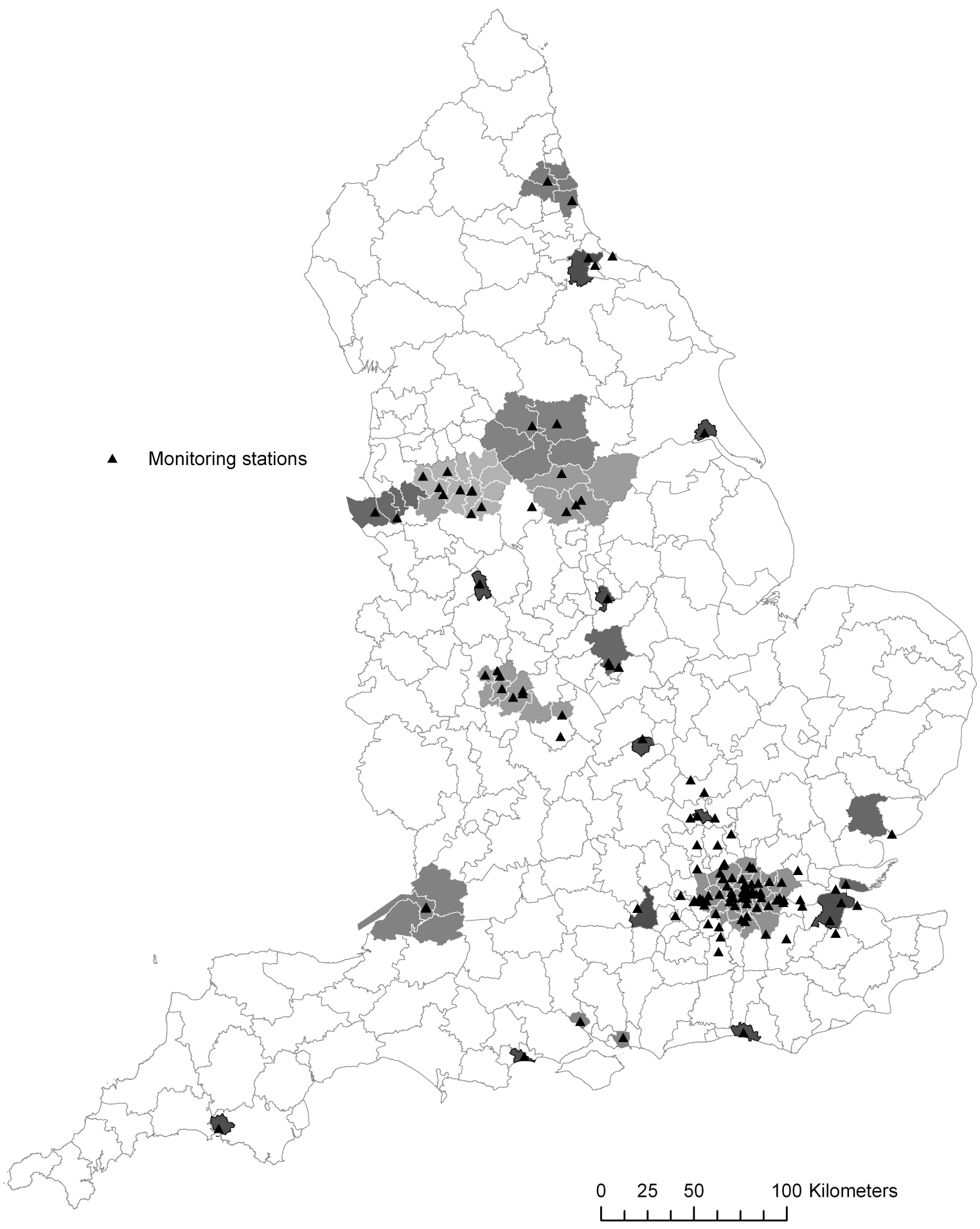

Figure 1: Geographical distribution of local authorities in estimation sample. Shaded areas indicate local authorities in estimation sample. Triangles show position of air pollution monitors. Local authorities with identical shading treated as cluster for estimation of standard errors. 
The local authority-year-quarter fixed effects control for unobserved differences between local authorities. These differences are allowed to change every three months. Quarterly fixed effects reflect the time period around which healthcare administration revolves. For example, hospital trusts' performance indicators are published on a quarterly basis. Quarters also represent the seasons that might coincide with changes in health behaviours. ${ }^{2}$ The yearweek effect captures the secular rise in emergency admissions and also controls flexibly for seasonal cycles, through, for example, the effect of week 2 allowed to be different in 2003 and 2004. Additionally, year-week dummies should sufficiently absorb the effects of influenza and other respiratory epidemics ${ }^{3}$. Identification, therefore, comes from variation in air pollution exposure within each week of the year and within each quarter of the year within a local authority.

As the dependent variable is a rate, I weight observations by the size of the local authority population. Weighting ensures admission rates with higher precision (from local authorities with larger populations) have more influence than admission rates with lower precision. The map in Figure 1 shows clusters of local authorities that share an air pollution monitoring station, causing correlation between the pollutant variables within these clusters. These local authority clusters coincide with counties. Therefore, I report robust standard errors that allow for serial correlation and clustering at the county level. ${ }^{4}$ Counties are made up of 4 to 14 local authorities. The 32 London boroughs form the county of Greater London.

\subsection{Lag structure}

Exposure to air pollution may have lagged effects on health, though the exact lag between exposure and admission to hospital is not obvious. Following Neidell (2009), I examine pollutant concentrations on the same day and the four preceding days. In the robustness tests, I assess the sensitivity of my results to different lag lengths.

I report the sum of the coefficients on the contemporaneous value and the four lags of the air pollutant $\left(\sum_{i=0}^{4} \beta_{i}\right)$, which can be interpreted as the total effect of a unit increase in pollutant concentration on day 1 on the number of emergency admissions on days 1 to 5. This approach lessens multiple comparison problems by reducing the number of t-tests from 10 (2 pollutants $\mathrm{x} 5$ days) to 2 . Additionally, since multicollinearity caused by serial correlation in the pollutants makes it difficult to obtain precise estimates of the individual lag coefficients, focussing on the total effect will increase precision. The standard error of the total effect is the square root of the sum of all elements of the variance-covariance matrix

\footnotetext{
${ }^{2}$ In particular, January/February/March represents the winter at the beginning of the new year, April/May/June the spring with longer days and more time spent outdoors, July/August/September the summer and the holiday season, October/November/December a time of intense economic activity and the run-up to Christmas.

${ }^{3}$ Weeks are the time period for which the Health Protection Agency collects data on consultations for influenza-like illness (Health Protection Agency 2011).

${ }^{4}$ Two of these counties, Avon and Cleveland, are former counties, as they were abolished and split into unitary authorities in 1996.
} 


$$
\left(\sqrt{\sum_{i=0}^{4} \sum_{l=0}^{4} \operatorname{Cov}\left[\widehat{\beta}_{i}, \widehat{\beta}_{l}\right]}\right) .
$$

\subsection{Avoidance behaviour}

I cannot observe directly whether parents avoid air pollution exposure of their children. However, if parents try to avoid air pollution, they are likely to respond to air pollution warnings. The UK government disseminates the air pollution forecast using traffic light colour-coding: green indicates low levels of air pollution, amber moderate and red high levels. Section 4.3 discusses in detail that because the majority of forecasts are "green" and "red" forecasts are extremely rare, an "amber" forecast is akin to an air pollution warning. I indirectly model avoidance behaviour by including an air pollution warning dummy variable, which takes the value one if an "amber" or "red" air pollution forecast has been issued. I include the contemporaneous value and four lags of the air pollution warning dummy - matching the lag length of the air pollution variables - and report the sum of the coefficients $\left(\sum_{i=0}^{4} \gamma_{i}\right)$.

Under the assumption that the air pollution warning dummy is a proxy for avoidance behaviour, i.e. a warning prompts parents to restrict their children's exposure to outdoor air pollution or take other preventive measures, the sum of the coefficients on the contemporaneous value and the four lags can be interpreted as the total effect of minimising air pollution exposure on day 1 on the number of hospital admissions on days 1 to 5 . Hence, we expect the coefficient to be negative.

Controlling for air pollution warnings will produce coefficient estimates for the air pollution variables that are net of the effect of reduced exposure to high air pollution on days when high levels of air pollution were predicted. To determine the bias in the pollutant coefficients when ignoring avoidance behaviour, I also run regressions without the air pollution warning dummy.

\subsection{Controls}

My measures of $\mathrm{NO}_{2}$ and $\mathrm{O}_{3}$ are taken at fixed-site outdoor monitors. Actual exposure to air pollution, however, also depends on indoor air quality. Indoor air quality can be worse than ambient air quality, for example because of tobacco smoke or paint fumes. Unfortunately, continuous measures of indoor air quality are not available. However, as the sources of indoor air pollution are different from the sources of outdoor air pollution, indoor and outdoor air pollution are likely to be uncorrelated. Therefore, missing data on indoor air quality is unlikely to cause omitted variable bias. ${ }^{5}$

Exposure to outdoor air pollution depends on the time children spend outdoors. Time spent outdoors, in turn, probably depends on the weather, the day of the week and whether a day is a public holiday or a school holiday. As these variables are likely to affect children's

\footnotetext{
${ }^{5}$ Indoor air quality could be correlated with air pollution warnings if, for example, in response to an air pollution warning people keep windows closed even while using a gas cooker, potentially causing downward bias in the estimate of the protective effect of an air pollution warning.
} 
health directly, they might confound the relationship between air pollution and hospital admissions. Therefore, I include controls for maximum and minimum temperature, total amount of rainfall and wind speed on the same day and the four preceding days $\left(\boldsymbol{M}_{a, t-i}\right)$ as well as dummy variables indicating the day of the week, public holidays in summer, public holidays in winter, bank holiday weekends, school holidays and school holiday weekends $\left(\boldsymbol{X}_{t}\right)$.

Certain weather conditions are conducive to high levels of air pollution. In the UK, the two main types of pollution episodes are winter and summer smogs. Winter smogs typically occur in cold, still and foggy weather, conditions that cause emissions to be trapped close to the ground and build up over time. Summer smogs occur in hot and sunny weather, because sunlight and high temperatures accelerate chemical reactions in pollutant mixtures that produce $\mathrm{O}_{3}$ (Department for Environment, Food and Rural Affairs 2006). Thus, it is likely that forecasters issue an air pollution warning when smog weather conditions are predicted. Therefore, if parents or children are aware of these weather conditions but not the air pollution warning and respond by taking preventive measures, smog weather conditions will confound the effect of air pollution warnings on hospital emergency admissions. Alternatively, if these weather conditions are good for children's health (net of their effects on pollutant concentrations), air pollution warnings will capture better weather rather than avoidance behaviour. To control for these potential confounding factors, I include two dummy variables that capture summer and winter smog weather conditions in the vector of meteorological controls $\boldsymbol{M}_{a, t-i .}{ }^{6}$ Details are in Appendix A.

\section{Data}

I use a rich data set derived from various administrative data sources. Here I provide an overview of the data; more details are in Appendix A.

\subsection{Hospital admissions}

The data on hospital emergency admissions are from Hospital Episode Statistics, a database that contains details of all admissions to National Health Service (NHS) hospitals in England. As the private sector does not provide emergency treatment ${ }^{7}$, the data should contain all emergency admissions.

The data contain information on the patient's local authority, which is derived from the postcode of the patient's home. Using this information, I extract the daily number of emergency admissions for each local authority. I generate admission counts based on the primary diagnosis for all respiratory diseases and symptoms (ICD-10 codes J00-J99, R05 and R06),

\footnotetext{
${ }^{6} \mathrm{~A}$ more mechanical approach to controlling for the confounding relationship between weather and air pollution warnings is the inclusion of polynomial and interaction terms in the weather variables. However, because of the lag structure the number of regressors would increase considerably.

${ }^{7}$ In the UK, private hospitals mainly provide elective healthcare services and some urgent treatment services.
} 
Table 1: Descriptive statistics

\begin{tabular}{lcccc}
\hline \hline & \multicolumn{4}{c}{ Standard deviation } \\
Variable & Mean & Overall & Between & Within \\
\hline Admissions for respiratory diseases & & & & \\
and symptoms (per 100,000 population) & 1.36 & 1.8 & 0.4 & 1.7 \\
Admissions for acute respiratory & & & & \\
infections (per 100,000 population) & 0.66 & 1.2 & 0.2 & 1.2 \\
Admissions for asthma (per 100,000 population) & 0.43 & 1.0 & 0.1 & 1.0 \\
Admissions for digestive diseases (per 100,000 pop.) & 2.19 & 2.3 & 0.6 & 2.2 \\
Nitrogen dioxide $\left(\mu \mathrm{g} / \mathrm{m}^{3}\right)$ & 34.6 & 16.8 & 7.8 & 14.9 \\
Ozone $\left(\mu \mathrm{g} / \mathrm{m}^{3}\right.$ ) & 55.6 & 25.1 & 5.8 & 24.4 \\
Air pollution warning & 0.28 & 0.4 & 0.1 & 0.4 \\
Maximum temperature $\left({ }^{\circ} \mathrm{C}\right)$ & 14.7 & 6.2 & 0.8 & 6.1 \\
Minimum temperature $\left({ }^{\circ} \mathrm{C}\right)$ & 7.3 & 5.1 & 0.6 & 5.0 \\
Rainfall (mm) & 2.0 & 4.0 & 0.5 & 4.0 \\
Wind speed (knots) & 7.7 & 3.8 & 1.3 & 3.6 \\
Summer smog weather & 0.04 & 0.2 & 0.0 & 0.2 \\
Winter smog weather & 0.03 & 0.2 & 0.2 & 0.2 \\
Population, age 5 to 19 & 60,749 & 41,324 & & \\
Population, all ages $($ for weighting) & 318,077 & 192,362 & & \\
\hline \hline
\end{tabular}

148,210 observations. Observations weighted by size of local authority population.

acute respiratory infections (ICD-10 codes J00-J22) and asthma (ICD-10 codes J45) for patients aged 5 to $19^{8}$. To obtain rates, I divide the admission counts by estimates of the population of 5 to 19 year olds in each local authority.

Descriptive statistics in Table 1 show that admission rates are extremely variable, with standard deviations larger than the means. Decomposition of the standard deviation into between and within variation shows that variation within local authorities dominates variation between local authorities. Acute respiratory infections constitute $50 \%$ of all respiratory admissions and asthma admissions account for $30 \%$ of respiratory admissions. Figure A-1 in Appendix A plots symmetric moving averages with a span of 10 days of the daily means of the three admission rates, showing strong seasonal variation. Admissions fall between January and August, increase steeply in September when children go back to school, drop around the October half-term holiday, rise in the run-up to Christmas and drop again during the Christmas holiday. Asthma admissions drive the peak in September, acute respiratory infections the peak in December.

\subsection{Air quality}

My measure of air quality are daily levels of nitrogen dioxide $\left(\mathrm{NO}_{2}\right)$ and ozone $\left(\mathrm{O}_{3}\right)$. European legislation sets legally binding concentration limits for these pollutants, for which reason

\footnotetext{
${ }^{8}$ I omit children under five because strong seasonality in emergency admissions for acute respiratory infections, which account for $70 \%$ of respiratory admissions, hampers identification, since the local authority-yearquarter fixed effects and the year-week effects absorb most of the variation.
} 
they are widely monitored. Other criteria pollutants that might affect respiratory health are particles with a diameter of less than $10 \mu \mathrm{m},{ }^{9}$ carbon monoxide and sulphur dioxide. ${ }^{10}$ However, they are positively correlated with $\mathrm{NO}_{2}$ and results in Section 6 show that in my sample they have no independent effect on hospital emergency admissions. With a mean of $0.52 \mathrm{mg} / \mathrm{m}^{3}$, carbon monoxide levels are much lower than in recent studies that found important effects on children's health. ${ }^{11}$ Therefore, I focus on $\mathrm{NO}_{2}$, a marker of trafficrelated, locally generated pollution, and on $\mathrm{O}_{3}$, which represents regional and transported pollution. $^{12}$

The air pollution data come from the UK Air Quality Archive augmented with data from several local monitoring networks. I drop all kerbside and roadside monitoring stations, because measurements taken at these sites are unlikely to represent air pollutant concentrations most people are exposed to. The majority of the remaining stations are classified as urban background sites, which should be representative of city-wide background conditions. Other important site types are urban centre and suburban and - for ozone measurements - rural. To assign daily air pollutant concentrations to local authorities, I calculate the inverse distance weighted mean of pollutant concentrations at monitors in a certain radius around a local authority's population-weighted centroid. This procedure is similar to Currie and Neidell (2005), more details are in Appendix A. I allow for differential radii according to population density: specifically, the radius is $5 \mathrm{~km}$ for boroughs in central London, $10 \mathrm{~km}$ for other London boroughs and $15 \mathrm{~km}$ for some outlying boroughs. For local authorities outside London the radius is $15 \mathrm{~km}$ if the area is less than $190 \mathrm{~km}^{2}$ and $20 \mathrm{~km}$ where the area is more than $190 \mathrm{~km}^{2}$. Figure 1 shows the position of the air pollution monitors in the estimation sample.

$\mathrm{NO}_{2}$ and $\mathrm{O}_{3}$ are measured in $\mu \mathrm{g} / \mathrm{m}^{3}$. To allow comparison of my results with those reported in the literature, I divide the $\mathrm{NO}_{2}$ and $\mathrm{O}_{3}$ values by 10 , so that the coefficients give the increase in the number of emergency admissions per $10 \mu \mathrm{g} / \mathrm{m}^{3}$ increase in the pollutant.

Descriptive statistics in Table 1 show that most of the variation in $\mathrm{NO}_{2}$ and $\mathrm{O}_{3}$ is within local authorities, providing support for my identification strategy. All of the observations comply with the limit value of $200 \mu \mathrm{g} / \mathrm{m}^{3}$ for the hourly mean of $\mathrm{NO}_{2}$ and only $1.8 \%$ of observations exceed the limit value of $120 \mu \mathrm{g} / \mathrm{m}^{3}$ for the 8-hour maximum mean of $\mathrm{O}_{3} .{ }^{13}$

\footnotetext{
${ }^{9}$ In response to emerging evidence that fine particulate matter (particles with a diameter of less than $2.5 \mu \mathrm{m}$ ) is responsible for significant negative effects on human health, the new EU Directive on ambient air quality, published in May 2008, adds objectives for this pollutant. However, only 5 monitoring stations measure fine particulate matter throughout the sample period.

${ }^{10}$ Also subject to European legislation and therefore regularly monitored are lead, polycyclic aromatic hydrocarbons, benzene and 1,3-butadiene. Lead affects the kidneys, gastrointestinal tract, joints, reproductive and nervous system and impairs intellectual development in young children. The other substances are subject to pollution control because of their carcinogenic properties (Department for Environment, Food and Rural Affairs 2007).

${ }^{11}$ In Currie and Neidell (2005) the sample mean of carbon monoxide is $1.998 \mathrm{ppm}$, which is equivalent to $2.32 \mathrm{mg} / \mathrm{m}^{3}$ when using a conversion factor of $1 \mathrm{ppm}=1.16 \mathrm{mg} / \mathrm{m}^{3}$. In Currie and Neidell (2005) the sample mean is $1.58 \mathrm{ppm}$, equivalent to $1.83 \mathrm{mg} / \mathrm{m}^{3}$.

${ }^{12} \mathrm{NO}_{2}$, along with carbon monoxide and volatile organic compounds, is an $\mathrm{O}_{3}$ precursor. $\mathrm{NO}_{2}$ and $\mathrm{O}_{3}$ are negatively correlated in my sample.

${ }^{13}$ For more details on limit values, see the Web Appendix.
} 
Figure A-2 in Appendix A plots symmetric moving averages with a span of 10 days of the daily means of $\mathrm{NO}_{2}$ and $\mathrm{O}_{3}$, showing a strong seasonal pattern. $\mathrm{NO}_{2}$ rises steeply between September and Christmas, then drops during the Christmas holidays, followed by a rebound in January. The seasonal cycle of $\mathrm{O}_{3}$ is the opposite: levels are lowest during the winter months, start rising in March, peak during the summer months and then fall again in September. This strong seasonal pattern might be reflected in other health related factors. Thus, it is important to account for seasonality in pollutants. Figure A-3 in Appendix A shows the residuals of $\mathrm{NO}_{2}$ and $\mathrm{O}_{3}$ after adjusting for the controls in Equation 1, demonstrating how the specification absorbs seasonal effects.

\subsection{Air pollution warnings}

The air pollution forecast is an index that ranges from 1 (very low) to 10 (very high). The index was developed by the Committee on the Medical Effects of Air Pollutants and is based on pollutant-specific evidence on health impacts. For example, the boundary between index points 3 and 4 is $100 \mu \mathrm{g} / \mathrm{m}^{3}$ for $\mathrm{O}_{3}$ and $250 \mu \mathrm{g} / \mathrm{m}^{3}$ for $\mathrm{NO}_{2}$ (Committee on the Medical Effects of Air Pollutants 2011). The air pollution forecast is issued in the afternoon for the following day. It is based on information from a number of sources, including weather forecasts, predictions of ground-level pollutant concentrations from a chemical transport model, forecast back-trajectory data indicating the origin of air expected to arrive over the UK, measured pollutant concentrations and satellite imagery. There is no precise algorithm for combining these information sources as "ultimately it is the expert judgement of the duty forecaster which determines how the available data are combined to form the forecast issued to the public" (Department for Environment, Food and Rural Affairs 2011). The forecaster predicts the levels of $\mathrm{NO}_{2}$ and $\mathrm{O}_{3}$ as well as carbon monoxide, particles with an aerodynamic diameter of 10 micrometer or less and sulphur dioxide, maps them onto the index and reports the index for the worst of the five pollutants.

The forecast is primarily disseminated using the following bands: low ( 1 to 3 ), moderate (4 to 6$)$, high (7 to 9 ) and very high (10). To aid interpretation, traffic light colour-coding represents the four bands: low $=$ green, moderate $=$ amber, high $=$ red and very high $=$ purple. The sample period contains no purple (very high) and very few red (high) forecasts. More than $70 \%$ of forecasts are green (low) and $27 \%$ of forecasts are amber (moderate). Users of the local authority funded airAlert and airText services receive a text message, voice message or e-mail alert when moderate (amber) or higher (red) levels of air pollution are forecast (Smallbone 2009). National weather reports on TV typically provide air quality information only when at least moderate levels of air pollution are expected. Individuals actively searching for air quality information will on average find a green forecast, making an amber forecast a noticeable change. Thus, it is likely that people interpret an amber (moderate) forecast as an air pollution warning. 14 Therefore, I create an air pollution warning dummy variable that

\footnotetext{
${ }^{14}$ Research on sign-post labelling of food products has shown that traffic light colour-coding is effective in
} 
takes the value zero if low air pollution is forecast and the value one if moderate or high air pollution is forecast. ${ }^{15}$

The forecast is produced for nine regions and eleven urban areas. The forecasting regions are coterminous with the nine Regions (formerly Government Office Regions), which are built up of complete local authorities, allowing an exact match of forecast to local authority. The geography of the urban areas for which forecasts are issued, however, is distinct from the administrative geography. Thus, where large parts of a local authority are part of an urban area I assign the forecast for the urban area, as this measure is more precise than a forecast issued for a whole region. On days when the forecast is missing I assign the region forecast instead. For local authorities which are not part of an urban area I assign the forecast for the region. Figure A-4 in Appendix A maps the local authorities in the estimation sample in relation to the Regions and urban areas. Figure A-5 plots monthly means of the air pollution warning dummy variable, showing few warnings between October and February and more regular warnings between March and September.

\subsection{Sample selection}

I restrict the estimation sample to local authorities with an area of less than $600 \mathrm{~km}^{2}$ and a total population of at least 150,000 to minimise measurement error in the air pollution variables and to obtain admission numbers that are large enough for linear regression analysis. Local authorities that fulfil these two criteria are also most likely to have an air pollution monitor within their boundaries, making the sample less arbitrary as observations are not dropped because of missing exposure variables. Of the 100 local authorities that satisfy my selection criteria 89 provide enough observations with no missing variables to be included in the analysis. My sample period is 2003 to 2007, because forecast data are available only from May 2002 onwards. Table A-4 in Appendix A provides more detail on sample selection.

\section{$5 \quad$ Results}

I begin by examining the impact of air pollution on emergency admissions for all respiratory diseases and symptoms, then I focus on acute respiratory infections and asthma, which are subsets of respiratory admissions, and finally I discuss the magnitudes of the estimated effects.

\footnotetext{
disseminating information about nutritional content (Grunert and Wills 2007).

${ }^{15}$ Dissemination of the air pollution forecast focuses on the band (low/moderate/high/very high). Individuals have to actively seek out advice on recommended actions, which is available on a website, through a Freephone telephone service and in a series of brochures. During the sample period the health advice about the four pollution bands was: Low - Effects are unlikely to be noticed even by individuals who know they are sensitive to air pollutants. Moderate - Mild effects, unlikely to require action, may be noticed amongst sensitive individuals. High - Significant effects may be noticed by sensitive individuals and action to avoid or reduce these effects may be needed (e.g. reducing exposure by spending less time in polluted areas outdoors). Asthmatics will find that their reliever inhaler is likely to reverse the effects on the lung. Very high - The effects on sensitive individuals described for 'High' levels of pollution may worsen (Committee on the Medical Effects of Air Pollutants 2011).
} 


\subsection{Admissions for all respiratory diseases and symptoms}

The first column of Table 2 shows the results for my main specification (Equation 1). The reported pollutant coefficients are the total effect $\left(\sum_{i=0}^{4} \beta_{i}^{j}\right)$ of a $10 \mu \mathrm{g} / \mathrm{m}^{3}$ increase in nitrogen dioxide $\left(\mathrm{NO}_{2}\right)$ and ozone $\left(\mathrm{O}_{3}\right){ }^{16}$ Both coefficient estimates are positive and statistically significant, suggesting that an increase in $\mathrm{NO}_{2}$ or $\mathrm{O}_{3}$ leads to an increase in hospital emergency admissions. For example, the coefficient estimate of 0.036 for $\mathrm{NO}_{2}$ suggests that a $10 \mu \mathrm{g} / \mathrm{m}^{3}$ increase in $\mathrm{NO}_{2}$ is associated with a total increase in respiratory emergency admissions on the same day and the following four days of 0.036 per 100,000 children aged 5 to 19 years. Since $\mathrm{NO}_{2}$ has a smaller standard deviation than $\mathrm{O}_{3}$ (16.8 versus 25.1) as well as a smaller range (interquartile range $\mathrm{NO}_{2}=22.4$ versus $\mathrm{O}_{3}=29.9$ ), a $10 \mu \mathrm{g} / \mathrm{m}^{3}$ increase in $\mathrm{NO}_{2}$ is a larger step than a $10 \mu \mathrm{g} / \mathrm{m}^{3}$ increase in $\mathrm{O}_{3}$. Therefore, we cannot compare the size of the coefficients directly. To examine the relative importance of the pollutants, Table 2 reports in square brackets below the coefficients the elasticities at the mean $\left(\left(\sum_{i=0}^{4} \beta_{i}^{N O_{2}}\right) \times \frac{\overline{N_{2}}}{\overline{a d m i s s i o n s^{k}}}\right)$. The elasticity of $\mathrm{NO}_{2}$ is $0.09\left(0.036 \times \frac{3.46}{1.36}\right)$, suggesting that a $1 \%$ increase in $\mathrm{NO}_{2}$ is associated with a $0.09 \%$ increase in emergency admissions. Even though the $\mathrm{O}_{3}$ coefficient is smaller, the elasticity is larger, suggesting that a $1 \%$ increase in $\mathrm{O}_{3}$ is associated with a $0.1 \%$ increase in emergency admissions.

These adverse effects of $\mathrm{NO}_{2}$ and $\mathrm{O}_{3}$ occur in a sample in which concentrations are mostly below the European Union's short-term limit values, which are intended to protect sensitive individuals from acute adverse effects during temporary exposure to these pollutants.

The reported coefficients on the variables indicating summer smog weather conditions, winter smog weather conditions or an air pollution warning are the total effect $\left(\sum_{i=0}^{4} \delta_{i}\right.$ and $\left.\sum_{i=0}^{4} \gamma_{i}\right)$. Thus, the estimate of -0.03 for the summer smog weather dummy suggests that summer smog weather conditions on day 1 are associated with a reduction in emergency admissions on days 1 to 5 of 0.03 per 100,000 population. The numbers in square brackets below the coefficients for the dummy variables are the percent change in the admission rate for a discrete change from 0 to 1, evaluated at the mean admission rate. Summer smog weather conditions thus reduce emergency admissions by $2.3 \%$ and winter smog weather conditions reduce admissions by $2.7 \%$, although neither of these coefficients are statistically significant. ${ }^{17}$ An air pollution warning is estimated to decrease the admission rate by $2.1 \%$, an effect size that is similar to the estimated effects of smog weather conditions. The coefficient is not statistically significant and the results in the second column of Table 2 from a regression without the air pollution warning dummy show that ignoring avoidance behaviour does not cause downward bias in the estimates of the pollutant effects.

\footnotetext{
${ }^{16} \mathrm{~A}$ table reporting the coefficients on the contemporaneous value and the lags of the regressors separately is available in the Web Appendix.

${ }^{17}$ The drop in admissions during summer smog weather might be due to positive effects of warmth on health. The negative coefficient on the winter smog weather dummy, however, is unlikely to be caused by positive effects of cold on health as low temperatures are generally associated with increases in respiratory diseases in children (Xu et al. 2012). Hence, the negative effect of winter smog weather might be due to avoidance behaviour.
} 
Table 2: Estimates of the association between air pollutants and hospital emergency admissions for respiratory diseases and symptoms in children aged 5 to 19 years

\begin{tabular}{lcc}
\hline \hline & Full specification & No warning \\
\hline $\mathrm{NO}_{2} / 10$ & $0.036^{* *}$ & $0.034^{* *}$ \\
& $(0.008)$ & $(0.008)$ \\
$\mathrm{O}_{3} / 10$ & {$[0.090]$} & {$[0.086]$} \\
& $0.026^{* *}$ & $0.025^{* *}$ \\
Summer smog weather & $(0.007)$ & $(0.007)$ \\
& {$[0.104]$} & {$[0.100]$} \\
& -0.032 & -0.032 \\
Winter smog weather & $(0.054)$ & $(0.057)$ \\
& {$[-2.315]$} & $-2.323]$ \\
Air pollution warning & -0.037 & -0.042 \\
& $(0.053)$ & $(0.054)$ \\
& {$[-2.711]$} & \\
\hline \hline
\end{tabular}

Robust standard errors in (round brackets), clustered at county level. Numbers in [square brackets] are elasticities at the mean for $\mathrm{NO}_{2}$ and $\mathrm{O}_{3}$ and percent change in admission rate (evaluated at the mean) for discrete change of Air pollution warning, Summer smog weather and Winter smog weather from 0 to 1 . Coefficients are sum of coefficients on contemporaneous value and four lags of regressors. Both regressions include local authority-year-quarter fixed effects and year-week fixed effects as well as dummies for day of week, public holidays in winter, public holidays in summer, bank holiday weekends, school holidays and school holiday weekends and contemporaneous value and four lags of maximum and minimum temperature, total amount of rainfall and mean wind speed. Observations weighted by size of local authority population. 148,210 observations in 89 local authorities with 23 county clusters in all regressions. *Significant at 5\%, ** significant at $1 \%$ 


\subsection{Admissions for specific respiratory causes}

The results discussed so far are for all respiratory diseases and symptoms. Table 3 presents results for two subsets of respiratory diseases: asthma and acute respiratory infections. The latter includes tonsillitis, influenza, pneumonia, bronchitis and bronchiolitis. A report by the World Health Organization - European Centre for Environment and Health (2005) reviews the biomedical literature on the mechanisms by which air pollution affects these two most common respiratory diseases in children. Experimental evidence indicates that air pollutants modulate the lungs' defence mechanism against bacteria and viruses, making children more susceptible to respiratory infections. Asthma appears to be connected to atopy - a tendency to develop allergic hypersensitivity reactions - and experimental studies have found that air pollutants enhance inflammatory airway responses in sensitized animals, pointing towards a causal relationship between air pollution and aggravation of asthma.

\subsubsection{Acute respiratory infections}

Results for acute respiratory infections are in the first column of Table 3. Again, the reported coefficients are the sum of the coefficients on the contemporaneous value and four lags of the regressors. ${ }^{18}$ The numbers in square brackets are elasticities at the mean and the percent change for a discrete change from 0 to 1 for the indicator variables. Results for the full sample in the top panel suggest that both $\mathrm{NO}_{2}$ and $\mathrm{O}_{3}$ are associated with admissions for acute respiratory infections.

For $\mathrm{O}_{3}$ the elasticity at the mean suggests that a $1 \%$ increase in $\mathrm{O}_{3}$ increases admissions for acute respiratory infections by $0.09 \%$, which is similar to the estimate for all respiratory admissions of $0.1 \%$. $\mathrm{O}_{3}$ causes airway inflammation (Department of Health 1997), making a relationship between $\mathrm{O}_{3}$ and respiratory infections biologically plausible. For $\mathrm{NO}_{2}$ the elasticity is 0.05 , about half the size of the elasticity estimate for all respiratory diseases, suggesting $\mathrm{NO}_{2}$ is less important for the subset of acute respiratory infections. A link between $\mathrm{NO}_{2}$ and acute respiratory infections is biologically plausible, though. $\mathrm{NO}_{2}$ is known as an irritant of the airways that increases susceptibility to respiratory infections by affecting the immune cells in the lungs (Department for Environment, Food and Rural Affairs 2010).

The coefficient on the summer smog weather dummy is, as before, negative but smaller. The coefficient estimate for the winter smog weather dummy, however, is positive, suggesting that winter smog weather conditions on day 1 increase admissions for acute respiratory infections on days 1 to 5 by $7 \%$. Presumably, it is near impossible to avoid infections during winter smog weather conditions: spending more time indoors likely results in crowding, easing the spread of germs. The estimate for the pollution warning dummy is also positive but relatively small, with a pollution warning estimated to lead to a $1.6 \%$ increase in admissions. Again, the reason might be that avoiding polluted outdoor air by staying indoors could foster close

\footnotetext{
${ }^{18} \mathrm{~A}$ table reporting the coefficients on the contemporaneous value and the lags of the regressors separately is available in the Web Appendix.
} 
Table 3: Estimates of the association between air pollutants and hospital emergency admissions for specific respiratory causes in children aged 5 to 19 years

\begin{tabular}{|c|c|c|c|c|}
\hline & \multicolumn{2}{|c|}{ Acute respiratory infections } & \multicolumn{2}{|c|}{ Asthma } \\
\hline & with warning & $\mathrm{w} / \mathrm{o}$ warning & with warning & $\mathrm{w} / \mathrm{o}$ warning \\
\hline $\begin{array}{l}\text { Full sample } \\
\mathrm{NO}_{2} / 10\end{array}$ & $\begin{array}{l}0.009 \\
(0.005) \\
{[0.048]}\end{array}$ & $\begin{array}{c}0.010 \\
(0.005) \\
{[0.051]}\end{array}$ & $\begin{array}{c}0.013 \\
(0.007) \\
{[0.106]}\end{array}$ & $\begin{array}{c}0.011 \\
(0.006) \\
{[0.092]}\end{array}$ \\
\hline $\mathrm{O}_{3} / 10$ & $\begin{array}{l}0.011^{*} \\
(0.005) \\
{[0.093]}\end{array}$ & $\begin{array}{c}0.011^{*} \\
(0.005) \\
{[0.095]}\end{array}$ & $\begin{array}{c}0.006 \\
(0.003) \\
{[0.073]}\end{array}$ & $\begin{array}{c}0.005 \\
(0.003) \\
{[0.061]}\end{array}$ \\
\hline Summer smog weather & $\begin{array}{r}-0.005 \\
(0.028) \\
{[-0.746]}\end{array}$ & $\begin{array}{r}-0.004 \\
(0.027) \\
{[-0.661]}\end{array}$ & $\begin{array}{r}-0.010 \\
(0.035) \\
{[-2.293]}\end{array}$ & $\begin{array}{r}-0.012 \\
(0.036) \\
{[-2.700]}\end{array}$ \\
\hline Winter smog weather & $\begin{array}{c}0.046 \\
(0.046) \\
{[6.924]}\end{array}$ & $\begin{array}{c}0.047 \\
(0.046) \\
{[7.137]}\end{array}$ & $\begin{array}{r}-0.029 \\
(0.025) \\
{[-6.818]}\end{array}$ & $\begin{array}{r}-0.034 \\
(0.025) \\
{[-7.905]}\end{array}$ \\
\hline Air pollution warning & $\begin{array}{c}0.011 \\
(0.025) \\
{[1.602]}\end{array}$ & & $\begin{array}{c}-0.033^{* *} \\
(0.010) \\
{[-7.841]}\end{array}$ & \\
\hline Sub-sample: March to & ctober & & & \\
\hline $\mathrm{NO}_{2} / 10$ & $\begin{array}{c}0.009 \\
(0.009) \\
{[0.046]}\end{array}$ & $\begin{array}{c}0.010 \\
(0.009) \\
{[0.055]}\end{array}$ & $\begin{array}{c}0.010 \\
(0.006) \\
{[0.075]}\end{array}$ & $\begin{array}{c}0.008 \\
(0.006) \\
{[0.062]}\end{array}$ \\
\hline $\mathrm{O}_{3} / 10$ & $\begin{array}{c}0.007 \\
(0.005) \\
{[0.079]}\end{array}$ & $\begin{array}{c}0.009 \\
(0.006) \\
{[0.095]}\end{array}$ & $\begin{array}{l}0.012^{* *} \\
(0.004) \\
{[0.173]}\end{array}$ & $\begin{array}{l}0.011^{* *} \\
(0.004) \\
{[0.159]}\end{array}$ \\
\hline Summer smog weather & $\begin{array}{r}-0.003 \\
(0.029) \\
{[-0.566]}\end{array}$ & $\begin{array}{r}-0.006 \\
(0.030) \\
{[-1.074]}\end{array}$ & $\begin{array}{c}-0.024 \\
(0.037) \\
{[-5.709]}\end{array}$ & $\begin{array}{r}-0.025 \\
(0.038) \\
{[-5.809]}\end{array}$ \\
\hline Winter smog weather & $\begin{array}{c}0.014 \\
(0.199) \\
{[2.404]}\end{array}$ & $\begin{array}{c}0.007 \\
(0.195) \\
{[1.149]}\end{array}$ & $\begin{array}{r}-0.048 \\
(0.104) \\
{[-11.280]}\end{array}$ & $\begin{array}{r}-0.043 \\
(0.106) \\
{[-9.986]}\end{array}$ \\
\hline Air pollution warning & $\begin{array}{l}0.030 \\
(0.023) \\
{[5.186]}\end{array}$ & & $\begin{array}{r}-0.030^{*} \\
(0.012) \\
{[-7.093]}\end{array}$ & \\
\hline
\end{tabular}

Robust standard errors in (round brackets), clustered at county level. Numbers in [square brackets] are elasticities at the mean for $\mathrm{NO}_{2}$ and $\mathrm{O}_{3}$ and percent change in admission rate (evaluated at the mean) for discrete change of Air pollution warning, Summer smog weather and Winter smog weather from 0 to 1 . Coefficients are sum of coefficients on contemporaneous value and four lags of regressors. All regressions include local authority-year-quarter fixed effects and year-week fixed effects as well as dummies for day of week, public holidays in winter, public holidays in summer, bank holiday weekends, school holidays and school holiday weekends and contemporaneous value and four lags of maximum and minimum temperature, total amount of rainfall and mean wind speed. Observations weighted by size of local authority population. 148,210 observations in 89 local authorities with 23 county clusters in top panel, 98,998 observations in 89 local authorities with 23 county clusters in bottom panel. *Significant at $5 \%, * *$ significant at $1 \%$ 
contact, which is conducive to spreading infections. However, none of these coefficients is statistically significant and results in the second column of Table 3 for the basic specification without the air pollution warning dummy show that there is no downward bias in pollutant effect estimates for acute respiratory infections when ignoring avoidance behaviour.

\subsubsection{Asthma}

Results for the full sample in the third column of the top panel of Table 3 are suggestive of an assocation between asthma admissions and the two pollutants. For $\mathrm{NO}_{2}$ the elasticity at the mean indicates that a $1 \%$ increase in the pollutant increases asthma admissions by $0.1 \%$, which is similar to the $\mathrm{NO}_{2}$ elasticity estimate of 0.09 for all respiratory admissions. For $\mathrm{O}_{3}$ the elasticity at the mean is 0.07 , around one-third smaller than the $\mathrm{O}_{3}$ elasticity estimate for all respiratory admissions. Results for the sub-sample of days between March and October in the bottom panel of Table 3 indicate a stronger effect of $\mathrm{O}_{3}$ during the summer months - when $\mathrm{O}_{3}$ levels tend to be higher. The elasticity at the mean of 0.17 is one-third larger than the estimate for the full sample and the coefficient is statistically significant at $1 \%$. These results are biologically plausible. $\mathrm{NO}_{2}$ enhances the response to allergens that produce constriction of the airways in asthmatics and $\mathrm{O}_{3}$ causes airway inflammation and a reduction in lung function, with a stronger inflammatory response in asthmatics (Department of Health 1997).

Focussing on the top panel of Table 3, the coefficient on the summer smog weather and winter smog weather dummies are both negative but statistically not significantly different from zero. ${ }^{19}$ The coefficient on the pollution warning dummy is negative and statistically significant at the $1 \%$ level, suggesting that a pollution warning reduces emergency admissions for asthma by $7.8 \%$. This relatively large estimate seems plausible, because advanced warning of raised levels of air pollution allows asthmatics to adjust the dose of their reliever medicine and to reduce activity outdoors (Committee on the Medical Effects of Air Pollutants 2000). The estimate is also economically plausible, because the costs of responding to an air pollution warning are very small if all that is required is to carry an inhaler. ${ }^{20}$ Coefficient estimates from regressions without the air pollution warning dummy in the fourth column of Table 3 are

\footnotetext{
${ }^{19}$ The coefficient on the winter smog dummy is relatively large, predicting that winter smog weather conditions on day 1 are associated with a $6.8 \%$ drop in asthma emergency admissions on days 1 to 5 . These results suggest avoidance in response to weather conditions that are conducive to high levels of air pollution and also known triggers of asthma attacks, see information on asthma triggers from Asthma UK, the UK's leading asthma charity: http://www.asthma.org.uk/knowledge-triggers-a-z.

${ }^{20}$ Theoretically, the effect of the difference between the costs of averting acute respiratory infections and the costs of averting asthma attacks is ambiguous. For asthma sufferers the costs might be negligible, so they may take precautionary measures irrespective of any air pollution warnings. In this case, I should find a very small coefficient on the air pollution warning dummy in the asthma regression and a larger coefficient in the acute respiratory infections model. Since I find a zero coefficient for acute respiratory infections and a relatively large coefficient for asthma, I conclude that avoidance costs are not negligible for asthma sufferers. Research evaluating the Sussex Air Quality Partnership's airAlert service supports this conclusion. The airAlert service sends air pollution warnings to respiratory sensitive people using SMS, voice message or email. $50 \%$ of surveyed users said that in response to a message they made sure they carried their reliever medication, which suggests they do not carry their reliever medication all the time (Smallbone 2009).
} 
between 8 an $20 \%$ smaller. As these smaller estimates are well within the confidence intervals of the estimates in the third column, the downward bias when ignoring avoidance behaviour is not statistically significant.

Overall, Table 3 shows that $\mathrm{NO}_{2}$ and $\mathrm{O}_{3}$ affect both acute respiratory infections and asthma. The adverse effect of $\mathrm{NO}_{2}$ is slightly stronger for asthma admissions. The magnitude of the $\mathrm{O}_{3}$ effects is roughly similar across disease categories, suggesting the potential benefits of avoidance are similar for both acute respiratory infections and asthma admissions. Avoidance behaviour, however, is evident only for asthma admissions, which suggests that the costs of avoidance differ across disease categories. Ignoring avoidance behaviour does not result in statistically significant underestimation of the effects of $\mathrm{NO}_{2}$ and $\mathrm{O}_{3}$ on asthma admissions.

\subsection{Magnitudes}

To gauge the economic significance of the estimated effects, I calculate the predicted reduction in the total number of admissions in my sample if $\mathrm{NO}_{2}$ and $\mathrm{O}_{3}$ were at the daily $25^{\text {th }}$ percentile (details below) and the predicted increase in the total number of admissions if there were no air pollution warnings. Estimating magnitudes requires simulations, because the lag structure does not allow simply multiplying the pollutant coefficients by a hypothetical reduction. Table 4 presents the results for all respiratory admissions in the top panel and for asthma admissions in the bottom panel. I begin by comparing the actual number of admissions with the predicted number of admissions when $\mathrm{NO}_{2}$ and $\mathrm{O}_{3}$ take their original values, before presenting the simulations with the daily $25^{\text {th }}$ percentile. The first row of both panels reports the actual number of admissions in the estimation sample. The second row gives the predicted number of admissions when $\mathrm{NO}_{2}$ and $\mathrm{O}_{3}$ take their original values, the baseline number of admissions for the simulations. It is calculated by using the coefficient estimates for the main specification (Equation 1) to predict the daily admission rates for the estimation sample, then multiplying the rates by the population and finally summing over all days. The difference between the actual and the predicted number of admissions is less than $1 \%$, suggesting the estimated model fits well on average.

To calculate the predictions with $\mathrm{NO}_{2}$ at the $25^{\text {th }}$ percentile, I first calculate the populationweighted $25^{\text {th }}$ percentile of $\mathrm{NO}_{2}$ for every day in my sample. Then, for every observation I replace the actual value of $\mathrm{NO}_{2}$ with the day's $25^{\text {th }}$ percentile of $\mathrm{NO}_{2}$ if the actual value is larger than the $25^{\text {th }}$ percentile. I use the daily $25^{\text {th }}$ percentile rather than the overall $25^{\text {th }}$ percentile to allow for seasonal variation and peak levels in winter and early spring. ${ }^{21}$ For

\footnotetext{
${ }^{21}$ Using the daily $25^{\text {th }}$ percentile seems a more realistic scenario than assuming $\mathrm{NO}_{2}$ could be as low as 22 $\mu \mathrm{g} / \mathrm{m}^{3}$, the overall $25^{\text {th }}$ percentile, on every day. Even at the $25^{\text {th }}$ percentile the limit value of a $40 \mu \mathrm{g} / \mathrm{m}^{3}$ annual mean is exceeded on 245 out of 1,811 days, with exceedances of more than $10 \mu \mathrm{g} / \mathrm{m}^{3}$ on 92 days in the five-year estimation sample. These high concentrations might be caused by an increase in emissions, but it is difficult to imagine reasons why emissions should be particularly high between $1^{\text {st }}$ and $5^{\text {th }}$ March 2004 or between $17^{\text {th }}$ and $23^{\text {rd }}$ November 2005. It is more likely that these peaks are caused by adverse atmospheric conditions, such as little wind and a shallow boundary layer, and are therefore inevitable as long as pollution abatement policies do not cut emissions to zero.
} 
Table 4: Simulated effects of replacing actual $\mathrm{NO}_{2}$ and $\mathrm{O}_{3}$ with daily $25^{\text {th }}$ percentile and switching off forecast dummy on total number of hospital admissions in 2003 to 2007

\begin{tabular}{lr}
\hline \hline \multicolumn{1}{c}{ All respiratory admissions } & Admissions \\
Actual number & 99,401 \\
Predicted number & 98,599 \\
$\mathrm{NO}_{2}$ at $25^{\text {th }}$ percentile & 96,426 \\
Predicted change & $-2,173$ \\
$\mathrm{O}_{3}$ at $25^{\text {th }}$ percentile & 96,793 \\
Predicted change & $-1,805$ \\
Warning dummy $=0$ for all observations & 99,187 \\
Predicted change & 588 \\
\hline \multicolumn{1}{c}{ Asthma admissions } & 30,914 \\
Actual number & 30,811 \\
Predicted number & 30,017 \\
$\mathrm{NO}_{2}$ at $25^{\text {th }}$ percentile & -793 \\
Predicted change & 30,417 \\
$\mathrm{O}_{3}$ at $25^{\text {th }}$ percentile & -393 \\
Predicted change & 31,482 \\
Warning dummy $=0$ for all observations & 671 \\
\hline Predicted change
\end{tabular}

Calculations are based on the estimation sample of 148,210 observations. $\mathrm{NO}_{2}$ at $25^{\text {th }}$ percentile has mean $25.6 \mu \mathrm{g} / \mathrm{m}^{3}$ and standard deviation 11.5, $\mathrm{O}_{3}$ at $25^{\text {th }}$ percentile has mean $45.9 \mu \mathrm{g} / \mathrm{m}^{3}$ and standard deviation 21.4. 
the same reason, I substitute the daily $25^{\text {th }}$ percentile of $\mathrm{O}_{3}$ for the actual value of $\mathrm{O}_{3} \cdot{ }^{22}$ By definition, every day one-quarter of the local authorities in my sample achieve these $\mathrm{NO}_{2}$ and $\mathrm{O}_{3}$ levels, making this simulation practically relevant.

The simulation results for all respiratory admissions suggest that reducing $\mathrm{NO}_{2}$ concentrations could have saved 2,173 hospital emergency admissions and reducing $\mathrm{O}_{3}$ levels might have avoided 1,805 emergency admissions in the local authorities covered by the sample for the 5 year sample period. To put a monetary value on the potential savings, I use the average cost per admission (taken from the national tariff, which covers over 500 hospital procedures provided in the NHS). ${ }^{23}$ The average cost of a respiratory admission is $£ 798$, therefore the potential savings from reducing $\mathrm{NO}_{2}$ are around $£ 1.7$ million $(£ 798 \times 2,173)$ and the savings from reducing $\mathrm{O}_{3}$ are around $£ 1.4$ million $(£ 798 \times 1,805)$. Additional benefits are fewer school absences and reductions in working days lost that might occur if a parent stays with their child during a hospital spell. Furthermore, there might be less quantifiable savings in terms of long-term health outcomes. For example, respiratory infections may increase the risk of developing asthma (Proud and Chow 2006) and have been hypothesised to affect lung growth (Gern et al. 2005).

To obtain an indication of the effectiveness of the air pollution forecast in reducing hospital admissions, I calculate the predicted increase in admissions if there were no air pollution warnings by setting the air pollution warning dummy to zero for all observations. I focus on asthma admissions, as the pollution warning coefficient is largest and statistically significant only for that admission type. The within sample prediction suggests that without the air pollution forecast there would have been 671 additional admissions for asthma. The average cost of an asthma admission is £699, so 671 avoided admissions in 2003 to 2007 saved $£ 469,000$. The cost of producing the air pollution forecast is around $£ 80,000$ to $£ 100,000$ per annum, ${ }^{24}$ equivalent to a maximum of $£ 500,000$ for the sample period. Therefore, the benefits of the air pollution forecast are roughly equal to the cost. As the air pollution forecast probably confers health benefits on the population outside the estimation sample, the total benefits are likely to exceed the costs.

\footnotetext{
${ }^{22}$ For $\mathrm{O}_{3}$ the overall $25^{\text {th }}$ percentile of $40 \mu \mathrm{g} / \mathrm{m}^{3}$ is unlikely to be attainable throughout the year, since $\mathrm{O}_{3}$ is produced by chemical reactions involving sunlight and therefore concentrations are much higher in the summer and also during sunny spells in winter. For instance, in February 2004 even the $25^{\text {th }}$ percentile reached more than $60 \mu \mathrm{g} / \mathrm{m}^{3}$ on several days.

${ }^{23}$ I use the Payment by Results tariff 2005/2006 (Department of Health 2004). The tariff specifies a price for a spell in hospital for each of about 530 Healthcare Resource Groups (HRG). In the estimation sample the most common HRGs are P03, Upper Respiratory Tract Disorders, with a non-elective spell tariff of $£ 540$ and P04, Lower Respiratory Tract Disorders without Acute Bronchiolitis, with a non-elective spell tariff of $£ 1,061$. Using the number of admissions in each HRG in 2005 as weights, the weighted average tariff is $£ 798$ for respiratory admissions and $£ 699$ for asthma admissions.

${ }^{24}$ Personal communication from Paul Willis, AEA Technology plc. For example, the contract between Defra and AEA for the 6-year period 2003 to 2008 specifies costs of $£ 554,144$, see Defra's website: http://randd.defra.gov.uk/Default.aspx?Menu=Menu\&Module=More\&Location=None\&Completed=0\& ProjectID $=15635 \#$ Description
} 


\section{$6 \quad$ Robustness tests}

First, I examine the robustness of my results to specification changes. These tests address the choice of pollutants, the definition of the air pollution warning variable and the number of lags of the pollutants. ${ }^{25}$ Next, I present a falsification test that uses hospital admissions for digestive diseases as a placebo outcome. Lastly, I extend the analysis by investigating interaction effects and spatial heterogeneity.

\subsection{Specification}

\subsubsection{Choice of pollutants}

My measure of air quality are $\mathrm{NO}_{2}$ and $\mathrm{O}_{3}$, two pollutants representative of the local air pollution mix. Other criteria pollutants that might affect respiratory health are particles with an aerodynamic diameter of $10 \mu \mathrm{m}$ or less $\left(\mathrm{PM}_{10}\right)$, carbon monoxide $(\mathrm{CO})$ and sulphur dioxide $\left(\mathrm{SO}_{2}\right)$. As they are positively correlated with $\mathrm{NO}_{2}$, the $\mathrm{NO}_{2}$ coefficient might be picking up the effect of these pollutants on hospital admissions. To investigate this potential omitted variable bias, Table 5 presents results from a multi-pollutant model that includes $\mathrm{PM}_{10}, \mathrm{CO}$ and $\mathrm{SO}_{2}$ in addition to $\mathrm{NO}_{2}$ and $\mathrm{O}_{3}$. Column 1 provides the baseline results for the model with $\mathrm{NO}_{2}$ and $\mathrm{O}_{3}$, estimated with the sample for which data on all 5 criteria pollutants are available. ${ }^{26}$ The estimates are similar to the main results in Table 2, with a $1 \%$ increase in $\mathrm{NO}_{2}$ or $\mathrm{O}_{3}$ associated with a $0.1 \%$ increase in emergency admissions for all respiratory diseases and symptoms. When including $\mathrm{PM}_{10}, \mathrm{CO}$ and $\mathrm{SO}_{2}$ in Column 2, the coefficient on $\mathrm{NO}_{2}$ drops by $10 \%$ but the $\mathrm{O}_{3}$ coefficient is unchanged. The $\mathrm{PM}_{10}$ and $\mathrm{SO}_{2}$ coefficients are zero. CO seems to have an independent effect on hospital admissions, which might be the reason for the $10 \%$ drop in the $\mathrm{NO}_{2}$ coefficient, suggesting that a small part of the association between $\mathrm{NO}_{2}$ and hospital admissions is due to its correlation with $\mathrm{CO}$. However, the estimated effect of $\mathrm{CO}$ is very small. The $\mathrm{CO}$ elasticity at the mean is about one-fifth of the $\mathrm{NO}_{2}$ and $\mathrm{O}_{3}$ elasticities and the coefficient is less precisely estimated, probably because of the very low levels of $\mathrm{CO}$ during the sample period. ${ }^{27}$ These results therefore support the focus on $\mathrm{NO}_{2}$ and $\mathrm{O}_{3}$.

\subsubsection{Definition of air pollution warning}

The air pollution warning dummy takes the value one if the 10-point air pollution forecast index takes the value four or higher, since it is the value at which the forecast becomes amber. To test the assumption that parents and children respond to the colour or band rather than the index value of the air pollution forecast, I split the air pollution warning dummy variable

\footnotetext{
${ }^{25} \mathrm{An}$ additional robustness test addressing the level of the fixed effects is reported in the Web appendix.

${ }^{26}$ Descriptive statistics for this sample are in the Web Appendix.

${ }^{27}$ The mean of $0.52 \mathrm{mg} / \mathrm{m}^{3}$ and even the maximum value of $4.8 \mathrm{mg} / \mathrm{m}^{3}$ are far below the limit value of 10 $\mathrm{mg} / \mathrm{m}^{3}$.
} 
Table 5: Robustness of the association between air pollutants and hospital emergency admissions to inclusion of additional air pollutants and splitting air pollution warning dummy variable into forecast index value dummies

\begin{tabular}{|c|c|c|c|c|}
\hline \multirow{2}{*}{$\mathrm{NO}_{2} / 10$} & \multicolumn{2}{|c|}{$\begin{array}{l}\text { Multi-pollutant model for } \\
\text { all respiratory admissions } \\
\text { With } \mathrm{PM}_{10}, \\
\text { Baseline } \quad \mathrm{CO} \text { and } \mathrm{SO}_{2}\end{array}$} & \multicolumn{2}{|c|}{ Forecast index dummies } \\
\hline & $\begin{array}{l}0.039^{* *} \\
(0.010) \\
{[0.103]}\end{array}$ & $\begin{array}{c}0.035^{* *} \\
(0.009) \\
{[0.091]}\end{array}$ & $\begin{array}{c}0.033^{* *} \\
(0.008) \\
{[0.083]}\end{array}$ & $\begin{array}{c}0.012 \\
(0.007) \\
{[0.096]}\end{array}$ \\
\hline $\mathrm{O}_{3} / 10$ & $\begin{array}{l}0.024^{* *} \\
(0.008) \\
{[0.100]}\end{array}$ & $\begin{array}{l}0.024^{* *} \\
(0.008) \\
{[0.099]}\end{array}$ & $\begin{array}{l}0.023^{* *} \\
(0.007) \\
{[0.092]}\end{array}$ & $\begin{array}{c}0.004 \\
(0.004) \\
{[0.055]}\end{array}$ \\
\hline $\mathrm{PM}_{10} / 10$ & & $\begin{array}{r}-0.000 \\
(0.012) \\
{[-0.000]}\end{array}$ & & \\
\hline $\mathrm{CO}$ & & $\begin{array}{l}0.048 \\
(0.027) \\
{[0.018]}\end{array}$ & & \\
\hline $\mathrm{SO}_{2} / 10$ & & $\begin{array}{r}-0.001 \\
(0.004) \\
{[-0.004]}\end{array}$ & & \\
\hline Pollution warning & $\begin{array}{r}-0.032 \\
(0.044) \\
{[-2.379]}\end{array}$ & $\begin{array}{r}-0.032 \\
(0.042) \\
{[-2.404]}\end{array}$ & & \\
\hline Forecast $=4$ & & & $\begin{array}{r}-0.039 \\
(0.045) \\
{[-2.889]}\end{array}$ & $\begin{array}{c}-0.036^{* *} \\
(0.012) \\
{[-8.461]}\end{array}$ \\
\hline Forecast $=5$ & & & $\begin{array}{c}0.024 \\
(0.047) \\
{[1.749]}\end{array}$ & $\begin{array}{c}-0.015 \\
(0.015) \\
{[-3.538]}\end{array}$ \\
\hline Forecast $=6$ & & & $\begin{array}{c}0.007 \\
(0.042) \\
{[0.516]}\end{array}$ & $\begin{array}{r}-0.035 \\
(0.044) \\
{[-8.174]}\end{array}$ \\
\hline Forecast $=7$ to 9 & & & $\begin{array}{r}0.159^{*} \\
(0.074) \\
{[11.651]}\end{array}$ & $\begin{array}{c}0.063 \\
(0.052) \\
{[14.804]}\end{array}$ \\
\hline Local auth. & 85 & 85 & 89 & 89 \\
\hline Observations & 117,355 & 117,355 & 148,210 & 148,210 \\
\hline
\end{tabular}

Robust standard errors in (round brackets), clustered at county level. 22 counties in Columns 1 and 2 , 23 counties in Columns 3 and 4. Numbers in [square brackets] are elasticities at the mean for $\mathrm{NO}_{2}, \mathrm{O}_{3}, \mathrm{PM}_{10}$, $\mathrm{CO}$ and $\mathrm{SO}_{2}$ and percent change in admission rate (evaluated at the mean) for discrete change of Air pollution warning and Forecast index from 0 to 1 . Coefficients are sum of coefficients on contemporaneous value and four lags of regressors. All regressions include local authority-year-quarter fixed effects, year-week fixed effects as well as dummies for day of week, public holidays in winter, public holidays in summer, bank holiday weekends, school holidays and school holiday weekends and contemporaneous value and four lags of maximum and minimum temperature, total amount of rainfall, mean wind speed, summer smog weather dummy and winter smog weather dummy. Observations weighted by size of local authority population. * Significant at $5 \%$, ** significant at $1 \%$ 
into its underlying index values: 4, 5 and 6, which are disseminated as amber (moderate) forecasts, and 7 to 9 , which are reported as red (high) forecasts. ${ }^{28}$

Table 5 presents results for all respiratory admissions in Column 3 and asthma admissions in Column 4. For all respiratory admissions pollutant coefficients drop by $10 \%$ but are still statistically significant at the $1 \%$ level. The small negative effect of air pollution warnings on all respiratory admissions seems to be driven by responses to forecasts of index value 4 , the threshold between green and amber forecasts. Forecasts of index value 4 are also the most common non-green forecasts. ${ }^{29}$ Focussing on asthma admissions, for which results in Table 3 indicate a statistically significant negative effect of air pollution warnings on emergency admissions, the size of the forecast coefficient does not increase with the index value. An air pollution forecast of index value 4 reduces asthma admissions by $8.5 \%$ and a forecast of index value 6 reduces admissions by $8.2 \%$, suggesting that parents and children respond to the change from green to amber rather than the change from index value 4 to index value $6 .{ }^{30}$

\subsubsection{Lag length}

The results discussed so far are the total effect of $\mathrm{NO}_{2}$ and $\mathrm{O}_{3}$ levels on the same day and the four preceding days. As the choice of four lags is somewhat arbitrary, I investigate whether different lag lengths affect the results. The range plots in Figure 2 show the sum of the coefficients and the $95 \%$ confidence intervals with no lags on the far left, consecutively adding one lag at a time, with the bar on the far right of the graph showing the coefficient sum from a model with eight lags of each of the pollutant, air pollution warning dummy and meteorological variables.

The first three plots present the coefficients for $\mathrm{NO}_{2}, \mathrm{O}_{3}$ and the air pollution warning dummy for the total of respiratory admissions; the fourth plot displays the coefficient on the air pollution warning dummy for asthma admissions. These show that as long as at least three lags (four lags for $\mathrm{NO}_{2}$ ) are included the choice of lag length does not affect the results. The size of the coefficients remains stable as more lags are added. Adding higher order lags, however, makes the coefficient sum estimates less precise.

\subsection{Falsification test}

To test that my results are not driven by some omitted health related factors that are correlated with air pollution or expected pollution levels at the local level, I estimate the model for

\footnotetext{
${ }^{28}$ Forecasts with index values 8 and 9 are too rare to allow estimation of separate coefficients. Out of the 148,210 observations in the estimation sample, 93 are index value 8 and 16 are index value 9 .

${ }^{29}$ Out of 148,210 observations, 31,523 are index 4, 6,932 are index 5 and 3,124 are index 6 .

${ }^{30}$ The positive coefficients on Forecast $=7$ to 9 probably pick up a non-linearity in the effect of $\mathrm{O}_{3}$ at extremely high levels of $\mathrm{O}_{3}$, as extremely high levels of $\mathrm{O}_{3}$ tend to coincide with a 7 to 9 forecast. In regressions that additionally include a dummy variable indicating an $\mathrm{O}_{3}$ level higher than the $99^{\text {th }}$ percentile $\left(133.11 \mu \mathrm{g} / \mathrm{m}^{3}\right)$ the coefficient on Forecast $=7$ to 9 is 0.127 (s.e. $\left.=0.079\right)$ for all respiratory admissions and 0.028 (s.e. $=0.051$ ) for asthma admissions. The coefficients on the dummy variable indicating an extremely high level of $\mathrm{O}_{3}$ are 0.159 (s.e. $\left.=0.101\right)$ and 0.152 (s.e. $\left.=0.065\right)$, respectively.
} 

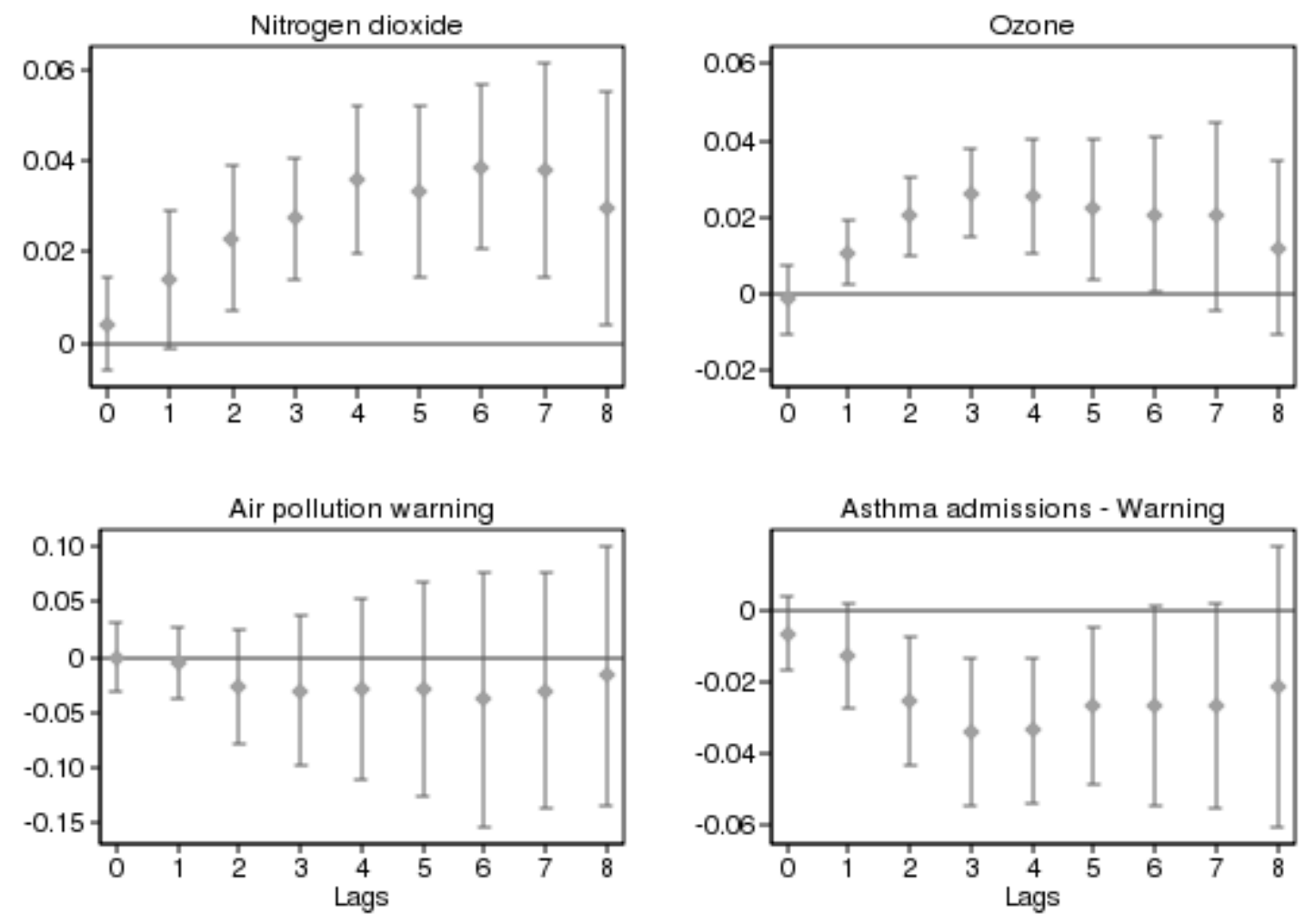

Figure 2: Sum of coefficients on contemporaneous value and specified number of lags of regressor and $95 \%$ confidence intervals 
emergency admissions that are unlikely to be affected by air pollution. These are admissions for digestive diseases and complaints. Digestive diseases and complaints are one of the leading causes of emergency admissions in children aged 5 to 19 years. ${ }^{31}$ Epidemiological time series studies have used digestive diseases as control diagnosis on the grounds that an association between air pollution and digestive disorders is biologically implausible (Petroeschevsky et al. 2001, Ballester et al. 2001).

Table 6: Falsification test: Estimates of the association between air pollutants and hospital emergency admissions for digestive diseases and complaints

\begin{tabular}{lcc}
\hline \hline & With pollution warning & Without pollution warning \\
\hline $\mathrm{NO}_{2} / 10$ & -0.012 & -0.013 \\
& $(0.010)$ & $(0.009)$ \\
$\mathrm{O}_{3} / 10$ & {$[-0.018]$} & {$[-0.020]$} \\
& -0.006 & -0.007 \\
Summer smog weather & $(0.007)$ & $(0.007)$ \\
& {$[-0.015]$} & $-0.017]$ \\
& -0.025 & $(0.055)$ \\
Winter smog weather & $(0.052)$ & {$[-1.019]$} \\
& {$[-1.155]$} & -0.072 \\
& -0.066 & $(0.075)$ \\
Air pollution warning & $(0.075)$ & {$[-3.271]$} \\
& $-3.032]$ & \\
\hline \hline
\end{tabular}

Robust standard errors in (round brackets), clustered at county level. Numbers in [square brackets] are elasticities at the mean for $\mathrm{NO}_{2}$ and $\mathrm{O}_{3}$ and percent change in admission rate (evaluated at the mean) for discrete change of Air pollution warning, Summer smog weather and Winter smog weather from 0 to 1 . Coefficients are sum of coefficients on contemporaneous value and four lags of regressors. All regressions include local authority-year-quarter fixed effects and year-week fixed effects as well as dummies for day of week, public holidays in winter, public holidays in summer, bank holiday weekends, school holidays and school holiday weekends and contemporaneous value and four lags of maximum and minimum temperature, total amount of rainfall and mean wind speed. Observations weighted by size of local authority population. 148,210 observations in 89 local authorities with 23 county clusters in all regressions. ${ }^{*}$ Significant at $5 \%,{ }^{*}$ significant at $1 \%$

Table 6 present the falsification test, replacing respiratory hospital emergency admissions as dependent variable with admissions for digestive diseases and symptoms (ICD-10 codes K00-K93 and R10-R19). The pollutant coefficients as well as the elasticities at the mean are small and go in the wrong direction. The coefficient on the air pollution warning dummy is negative but very small, suggesting that a pollution warning reduces emergency admissions for digestive diseases by $0.6 \%$. When omitting the air pollution warning dummy, the

\footnotetext{
${ }^{31}$ The most common cause of hospital emergency admissions in children aged 5 to 19 years are injuries (ICD-10 codes S00-S99). Serious injuries requiring hospital admission can be caused by traffic accidents and therefore injuries could be related to traffic density, which in turn is associated with air pollution, making injuries an unsuitable placebo outcome.
} 
estimated negative pollutant effects increase in absolute value. None of the estimates are statistically significant. Thus, it is unlikely that omitted factors confound the relationship between respiratory hospital admissions, air pollutants and pollution warnings.

\subsection{Interaction effects}

The protective effect of an air pollution warning potentially depends on the level of pollution. To investigate potential interaction effects, Table 7 reports results from regressions that include interaction terms between the pollutant concentrations and the air pollution warning dummy. As before, the reported coefficients are the sum of the coefficients on the contemporaneous value and four lags of the regressors. For all respiratory admissions and asthma admissions, the coefficients on the the interaction terms are positive, while the coefficient on the warning dummy is negative, which suggests that the protective effect of an air pollution warning decreases as $\mathrm{NO}_{2}$ or $\mathrm{O}_{3}$ increase relative to their normal level. ${ }^{32}$ The reason may be that the usual actions taken in response to air pollution warnings, such as carrying an asthma inhaler, are not sufficient at very high levels of air pollution, resulting in a tailing off of the impact of warnings. For acute respiratory infections neither the warning coefficient nor the coefficients on the interactions are statistically significant, mirroring the results in Table 3 that show no impact of air pollution warnings for this subset.

\subsection{Spatial heterogeneity}

The estimation sample covers diverse locations with different pollution experiences. To explore variations in the relationship between air pollution and hospital admissions across areas, I split the sample into low, medium and high pollution local authorities using the terciles of the distribution of the local authorities' long-term average of $\mathrm{NO}_{2} \cdot{ }^{33}$ As a marker of traffic-related pollution, $\mathrm{NO}_{2}$ is well suited to determine high pollution areas. Figure 3 presents estimates for all respiratory admissions and asthma admissions.

For all respiratory admissions, the marginal effect of $\mathrm{NO}_{2}$ is highest for local authorities in the top tercile of the long-term $\mathrm{NO}_{2}$ distribution. The marginal effect of $\mathrm{O}_{3}$ is considerably larger in the middle and top tercile than in the bottom tercile. The falling trend in the effect of air pollution warnings on hospital admissions suggests more avoidance behaviour in more polluted areas, though the effect size is small and statistically insignificant for all terciles.

For asthma admissions, there is no clear trend for the pollutant coefficients, apart from smaller point estimates for the least polluted local authorities. The coefficients on the warning

\footnotetext{
${ }^{32}$ The flip side of this result is that an air pollution warning increases the marginal effects of $\mathrm{NO}_{2}$ and $\mathrm{O}_{3}$ on hospital emergency admissions. For a detailed discussion of these findings, including a table with predicted admission rates for varying values of $\mathrm{NO}_{2}$ and $\mathrm{O}_{3}$, see the Web Appendix.

${ }^{33}$ As the panel is unbalanced, I cannot simply calculate the mean of $\mathrm{NO}_{2}$ for each local authority. Instead, I regress $\mathrm{NO}_{2}$ on the year-week dummies and dummy variables indicating the day of the week, public holidays in summer, public holidays in winter, bank holiday weekends, school holidays and school holiday weekends and calculate the local authority means of the residuals of this regression.
} 
Table 7: Estimates of the association between air pollutants and hospital emergency admissions from regression models with interaction terms between pollutant concentrations and air pollution warning dummy

\begin{tabular}{lccc}
\hline \hline & $\begin{array}{c}\text { All respiratory } \\
\text { admissions }\end{array}$ & $\begin{array}{c}\text { Acute respiratory } \\
\text { infections }\end{array}$ & Asthma \\
\hline $\mathrm{NO}_{2} / 10$ & $0.028^{*}$ & $0.014^{*}$ & 0.005 \\
& $(0.010)$ & $(0.006)$ & $(0.007)$ \\
$\mathrm{O}_{3} / 10$ & 0.012 & 0.007 & -0.001 \\
& $(0.007)$ & $(0.005)$ & $(0.004)$ \\
Air pollution warning & -0.208 & 0.012 & $-0.161^{* *}$ \\
& $(0.110)$ & $(0.059)$ & $(0.044)$ \\
$\mathrm{NO}_{2}$ x Warning & 0.010 & -0.013 & $0.016^{* *}$ \\
& $(0.014)$ & $(0.008)$ & $(0.005)$ \\
$\mathrm{O}_{3}$ x Warning & $0.026^{*}$ & 0.008 & $0.012^{* *}$ \\
& $(0.009)$ & $(0.005)$ & $(0.004)$ \\
\hline \hline
\end{tabular}

Robust standard errors in (round brackets), clustered at county level. Coefficients are sum of coefficients on contemporaneous value and four lags of regressors. All regressions include local authority-year-quarter fixed effects and year-week fixed effects as well as dummies for day of week, public holidays in winter, public holidays in summer, bank holiday weekends, school holidays and school holiday weekends and contemporaneous value and four lags of maximum and minimum temperature, total amount of rainfall, mean wind speed, summer smog weather dummy and winter smog weather dummy. Observations weighted by size of local authority population. 148,210 observations in 89 local authorities with 23 county clusters in all regressions. *Significant at $5 \%,{ }^{* *}$ significant at $1 \%$
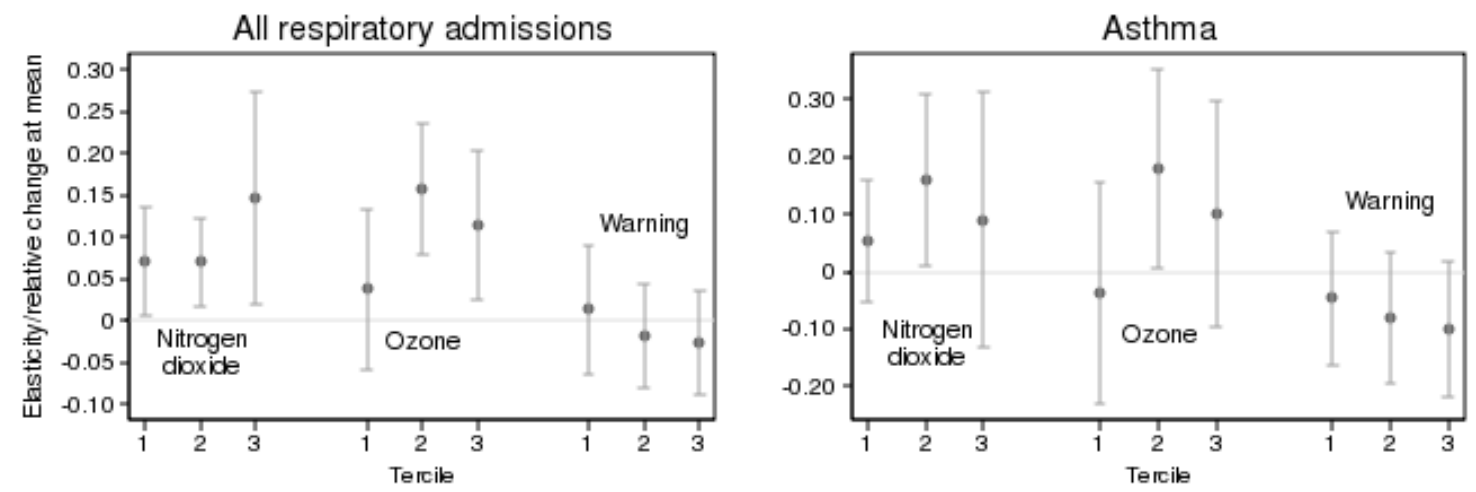

Figure 3: Estimates of the association between air pollutants and hospital emergency admissions for terciles of local authority mean $\mathrm{NO}_{2}$. Points are elasticities at the mean for $\mathrm{NO}_{2}$ and $\mathrm{O}_{3}$ and proportional change in admission rate (evaluated at the mean) for discrete change of Air pollution warning from 0 to 1 , with $95 \%$ confidence intervals. 


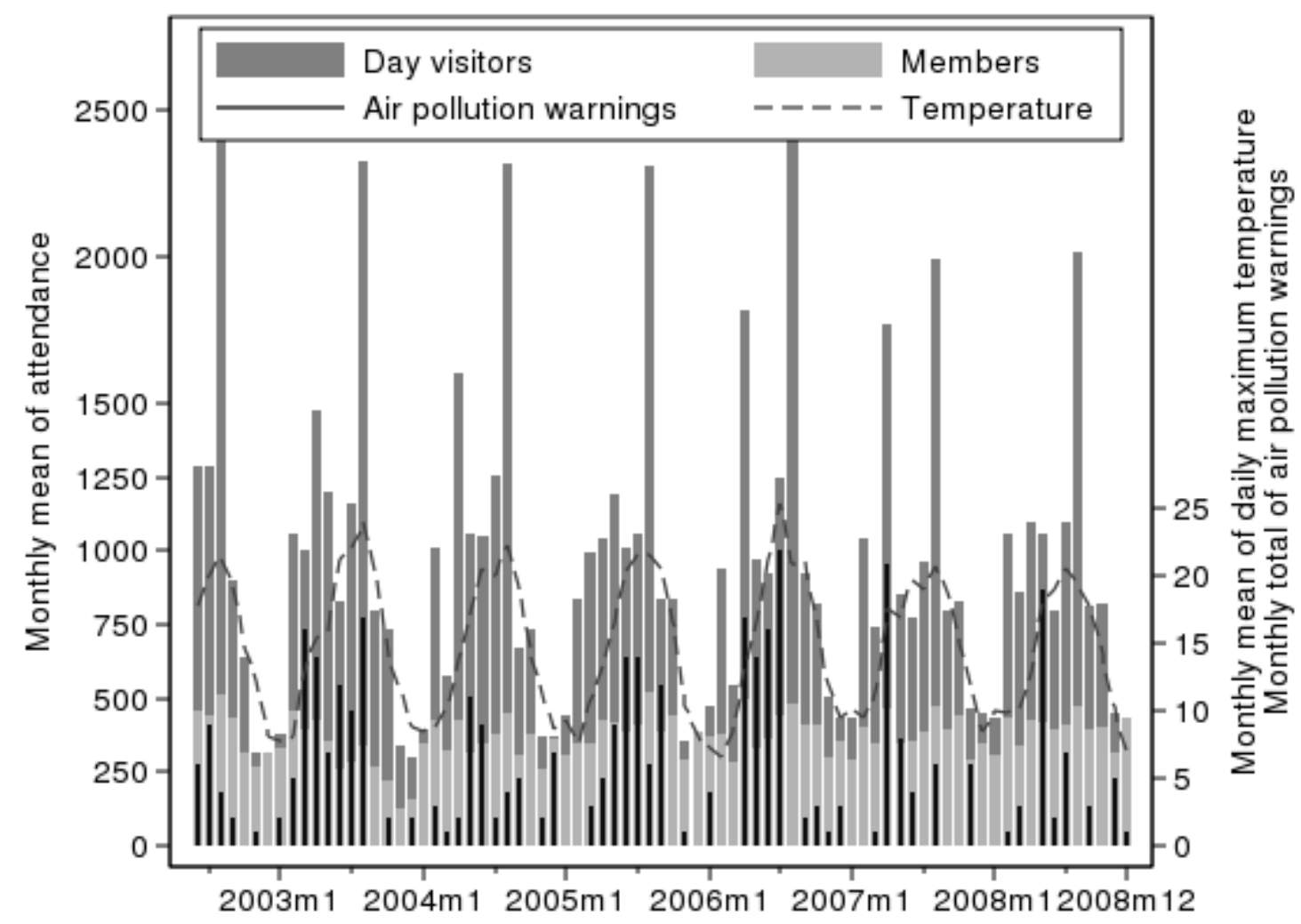

Figure 4: Monthly means of paying visitors to Bristol Zoo Gardens, daily maximum temperature and monthly total of air pollution warnings

dummy show a clear increase in the protective effect of an air pollution warning as long-term $\mathrm{NO}_{2}$ levels increase, which suggests that parents and children in high pollution areas adapt by responding to air pollution warnings.

\section{Direct evidence of avoidance behaviour: Visitors to Bristol Zoo}

The negative coefficient on the air pollution warning dummy variable provides indirect evidence of avoidance behaviour. For direct evidence of a behavioural response to air pollution warnings, I examine daily visitor counts to Bristol Zoo Gardens. Zoos are attractive destinations for families with children. Even with some animal houses under cover, most people will consider a zoo visit to be an outdoor activity and therefore susceptible individuals might adjust their plans to the air pollution forecast. An integral part of a zoo visit are the weather conditions. Demand drops in bad weather and because of the fixed entrance fee, which allows only for quantity adjustment, visitor numbers will drop considerably. As weather conditions also feed into the air pollution forecast, they are potential confounders.

Bristol Zoo collect data on day visitors who pay the individual admission price (those 
over age 3) and on those who have an annual membership that entitles them to unlimited visits for a year. Members tend to be local residents, so for them a zoo visit likely requires less organisational effort than for day visitors. Local residents could also be more aware of information about air quality. Hence, there is a difference in the cost of avoidance between day visitors and members. Figure 4 shows monthly mean attendance for day visitors and members aged three years and above for June 2002 to December 2008 (details in Appendix B) as well as monthly means of the daily maximum temperature and the monthly total of air pollution warnings. Attendance by day visitors peaks in August. Visits by members also peak in August, but there is another peak of similar size around Easter. The pattern in attendance reflects the seasonal temperature cycle. Similarly, the number of pollution warnings is larger during the summer months. The number of day visitors seems unresponsive to pollution warnings. Some of the peaks in warnings even seem to coincide with peaks in day visitor numbers.

\subsection{Estimation method}

To examine the effect of air pollution warnings on the two groups, I estimate separately for the two groups:

$$
\ln \left(\text { attendance }_{t}^{k}\right)=\beta \text { warning }_{t}+\boldsymbol{M}_{t}^{\prime} \boldsymbol{\delta}+\boldsymbol{X}_{t}^{\prime} \boldsymbol{\lambda}+\tau_{m(t), y(t)}+\varepsilon_{t}
$$

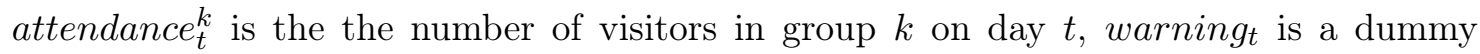
variable taking the value zero if low air pollution is forecast for day $t$ and the value one if moderate or high air pollution levels are forecast, $\boldsymbol{M}_{t}^{\prime}$ is a vector of meteorological variables on day $t, \boldsymbol{X}_{t}^{\prime}$ is a vector of dummy variables indicating the day of the week, public holidays in summer, public holidays in winter, bank holiday weekends, school holidays and school holiday weekends. $\tau_{m(t), y(t)}$ is a year-month effect and $\varepsilon_{t}$ the error term. The meteorological variables $\boldsymbol{M}_{t}^{\prime}$ are the same as in the regressions for hospital emergency admissions: maximum and minimum temperature, total amount of rainfall, wind speed, summer smog weather dummy and winter smog weather dummy.

\subsection{Results}

Table 8 presents results for day visitors in Column 1 and for zoo members in Column 2 . The coefficients on the weather variables show that both day visitors and members respond similarly to the main features of the bundle of services offered by Bristol Zoo. As the dependent variables are in natural logarithms, we can interpret the coefficient estimates as the percent change in visitor numbers per unit change in the explanatory variables. A drop in daily

maximum temperature from the $75^{\text {th }}$ percentile to the $25^{\text {th }}$ percentile is associated with a $25 \%$ drop in visitor numbers. An increase in daily minimum temperature and wind speed from the $25^{\text {th }}$ percentile to the $75^{\text {th }}$ percentile reduces attendance by around $10 \%$ and - based 
on the distribution of rain days ${ }^{34}$ only - a jump from the $25^{\text {th }}$ to the $75^{\text {th }}$ percentile in rainfall $(6.19 \mathrm{~mm})$ is associated with a $9 \%$ drop in visitors.

Table 8: Estimates of the association between air pollution warnings and zoo attendance

\begin{tabular}{lcc}
\hline \hline & Day visitors & Members \\
\hline Air pollution warning & 0.029 & $-0.061^{*}$ \\
& $(0.030)$ & $(0.028)$ \\
Max. temperature & $0.029^{* *}$ & $0.026^{* *}$ \\
& $(0.006)$ & $(0.005)$ \\
Min. temperature & $-0.017^{* *}$ & $-0.017^{* *}$ \\
& $(0.005)$ & $(0.005)$ \\
Rain & $-0.015^{* *}$ & $-0.014^{* *}$ \\
& $(0.002)$ & $(0.002)$ \\
Wind speed & $-0.018^{* *}$ & $-0.021^{* *}$ \\
Summer smog weather & $(0.003)$ & $(0.003)$ \\
& $-0.109^{*}$ & $-0.154^{* *}$ \\
Winter smog weather & $(0.050)$ & $(0.058)$ \\
& -0.031 & -0.025 \\
\hline \hline
\end{tabular}

Newey-West standard errors allowing for autocorrelation up to lag 10 in (round brackets). All regressions include year-month dummies, dummies for day of week, public holidays in winter, public holidays in summer, bank holiday weekends, school holidays and school holiday weekends. 2382 observations in both regressions. ${ }^{*}$ Significant at $5 \%,{ }^{*}$ significant at $1 \%$

The response to air pollution warnings differs between the two groups of visitors. For day visitors, the coefficient on the air pollution warning dummy is positive but not statistically significant, suggesting that a pollution warning increases visitor numbers by $3 \%$. For members, however, the coefficient is negative and statistically significant at the $5 \%$ level, with an estimated $6 \%$ drop in attendance in response to an air pollution warning. This result is economically plausible. In a country with relatively low air pollution levels, air quality is a marginal feature of the zoo package. If the costs of postponing a visit are low, as they are for members, who as local residents can just drop in for a quick visit and also have easy access to air quality information, a small gain in utility from postponing a visit until a day with a better air quality forecast will exceed the cost of postponing. For day visitors, however, the utility gain is likely to be smaller than the cost, as they may have planned their visit well in advance and kept the day free from other commitments, so they can stay for the day to get the most for their entrance fee (around $£ 40$ for a family of four). Additionally, obtaining information about local air quality could require more effort for day visitors who come from outside the Bristol conurbation.

These estimates provide direct evidence supporting the finding from the main analysis that individuals practise avoidance behaviour only when it is less costly.

\footnotetext{
${ }^{34} \mathrm{~A}$ rain day is defined as a day during which precipitation of $0.2 \mathrm{~mm}$ or more has been recorded.
} 


\section{Conclusion}

Exploiting daily data on air pollution in England, a country with internationally low levels of air pollution, for a period of 5 years, I find that a $10 \%$ increase in $\mathrm{NO}_{2}$ or $\mathrm{O}_{3}$ increases the rate of hospital emergency admissions for respiratory diseases and symptoms in children aged 5 to 19 years by around 1\%. The results are similar for asthma and acute respiratory infections, two subsets of respiratory diseases and symptoms. These adverse effects of $\mathrm{NO}_{2}$ and $\mathrm{O}_{3}$ occur in a sample in which concentrations mostly comply with air quality standards. Air pollution warnings affect only the subset of asthma admissions. The direct effect is an $8 \%$ reduction in admissions but omitting the control for air pollution warnings does not lead to statistically significant underestimation of the effects of $\mathrm{NO}_{2}$ and $\mathrm{O}_{3}$ on asthma admissions. The cost of avoidance is low for asthmatics, as they can respond to a pollution warning by carrying their inhaler and adjusting the dose of their reliever medicine. Preventing acute respiratory infections would require staying indoors, which is much more costly for children and their parents. Thus, parents and children seem to respond to air pollution warnings only if the costs are low. Results from an analysis of daily attendance data from Bristol Zoo confirm this finding. A pollution warning reduces attendance by members by $6 \%$, whereas the (statistically insignificant) coefficient estimate for day visitors suggests a $3 \%$ increase in visits. Obtaining information about local air quality and changing the day of a visit is less costly for members compared to visitors who come from further away.

Comparing my estimates to the small number of studies that focus on children gives an idea of the relative size of the harmful effect of air pollution in an urbanised country which has relatively low levels of pollution. Examining asthma hospitalisations between March and October, Neidell (2009) estimates an elasticity at the mean of 0.22 for $\mathrm{O}_{3}$ and finds that ignoring avoidance behaviour in response to smog alerts results in statistically significantly underestimating the effect of $\mathrm{O}_{3}$ by more than $60 \%$. Investigating the effect of smog alerts on visitor numbers at Los Angeles Zoo, he finds a drop in attendance of $15 \%$ in general and of $19 \%$ for the subset of members' visits. My estimate of the effect of $\mathrm{O}_{3}$ on asthma admissions (0.17) is similar to Neidell's, but his estimate of the downward bias when ignoring avoidance behaviour is much larger than mine. However, a smog alert is a more extreme event than an air pollution warning predicting moderate levels of air pollution and is therefore likely to elicit a stronger response. Additionally, the mean level of $\mathrm{O}_{3}$ in Neidell's sample is 160 $\mu \mathrm{g} / \mathrm{m}^{3}$, which is three times larger than my sample mean. So the perceived benefits of staying indoors on days when $\mathrm{O}_{3}$ levels are even higher are probably considerable. Compared to the epidemiological literature, my estimates of the effects of $\mathrm{NO}_{2}$ and $\mathrm{O}_{3}$ are larger. de Leon et al. (1996), Atkinson et al. (1999) and Anderson et al. (2001) find at mean $\mathrm{NO}_{2}$ levels that are twice as high as in my sample elasticities at the mean between 0.03 and 0.05 , half the size of my estimates. For $\mathrm{O}_{3}$, de Leon et al. (1996), Sunyer et al. (1997), Petroeschevsky et al. (2001), Burnett et al. (1994) and Fusco et al. (2001) find elasticities at the mean between 0.004 and 0.06, up to two-thirds of my estimates. These studies assign one air pollution measure to the 
whole study area, so their estimates suffer from measurement error. My results illustrate the benefits of using more precise and appropriately allocated pollution measures.

In conclusion, my results suggest that the harmful effect of ozone is similar to that estimated for Southern California and that the effect of nitrogen dioxide is higher than found in other studies of children. In addition, my results show that whether individuals respond to air quality information depends on the costs and benefits of doing so: where costs are low and the benefits clear, responses are higher. This finding suggests that a recent move in the UK to increase the number of moderate or high forecasts (Committee on the Medical Effects of Air Pollutants 2011) may not bring about the desired prevention of adverse health effects from short-term elevations in air pollution levels as people appear to respond to the forecast only where it is less costly to do so.

\section{Acknowledgements}

This work was supported by the Economic and Social Research Council through a studentship. I thank Carol Propper for her advice and continuous guidance and Frank Windmeijer, Simon Burgess, Helen Simpson, two anonymous referees and editor Nigel Rice for their helpful comments.

\section{Appendix A Description of main dataset}

Table A-1 provides the data sources for all variables except air pollution.

Figure A-1 plots symmetric moving averages with a span of 10 days of the daily means of the hospital emergency admission rates. It shows strong seasonal variation in admissions for all respiratory diseases and symptoms, with a gentle downwards slope between January and August, a step increase in September, when children go back to school after the summer holidays, a drop around the October half-term holiday, followed by rising rates in the run-up to Christmas and another drop during the Christmas holiday. Asthma admissions drive the peak in September, acute respiratory infections the peak in December.

Table A-2 lists the monitoring networks from whose websites I have downloaded air pollution data. I drop all provisional values as well as all kerbside and roadside monitoring stations. As some data come in volume ratios, I convert them into mass units using the conversion factors used for reporting data to the European Commission, which are $1 \mathrm{ppb}=$ $1.91 \mu \mathrm{g} / \mathrm{m}^{3}$ for $\mathrm{NO}_{2}$ and $1 \mathrm{ppb}=2.00 \mu \mathrm{g} / \mathrm{m}^{3}$ for $\mathrm{O}_{3}$. I calculate the daily mean of $\mathrm{NO}_{2}$ and the daily maximum 8-hour running mean of $\mathrm{O}_{3}$ for each of the monitoring stations and then

Table A-1: Data sources

\begin{tabular}{ll}
\hline \hline Variable & Source \\
\hline Hospital emergency admissions & Hospital Episode Statistics (HES) \\
Local authority population & Mid-year population estimates from \\
& Office for National Statistics \\
Air pollution forecast & AEA Technology plc. \\
Temperature, rainfall, wind speed & Met Office - MIDAS Land Surface Stations data \\
\hline \hline
\end{tabular}




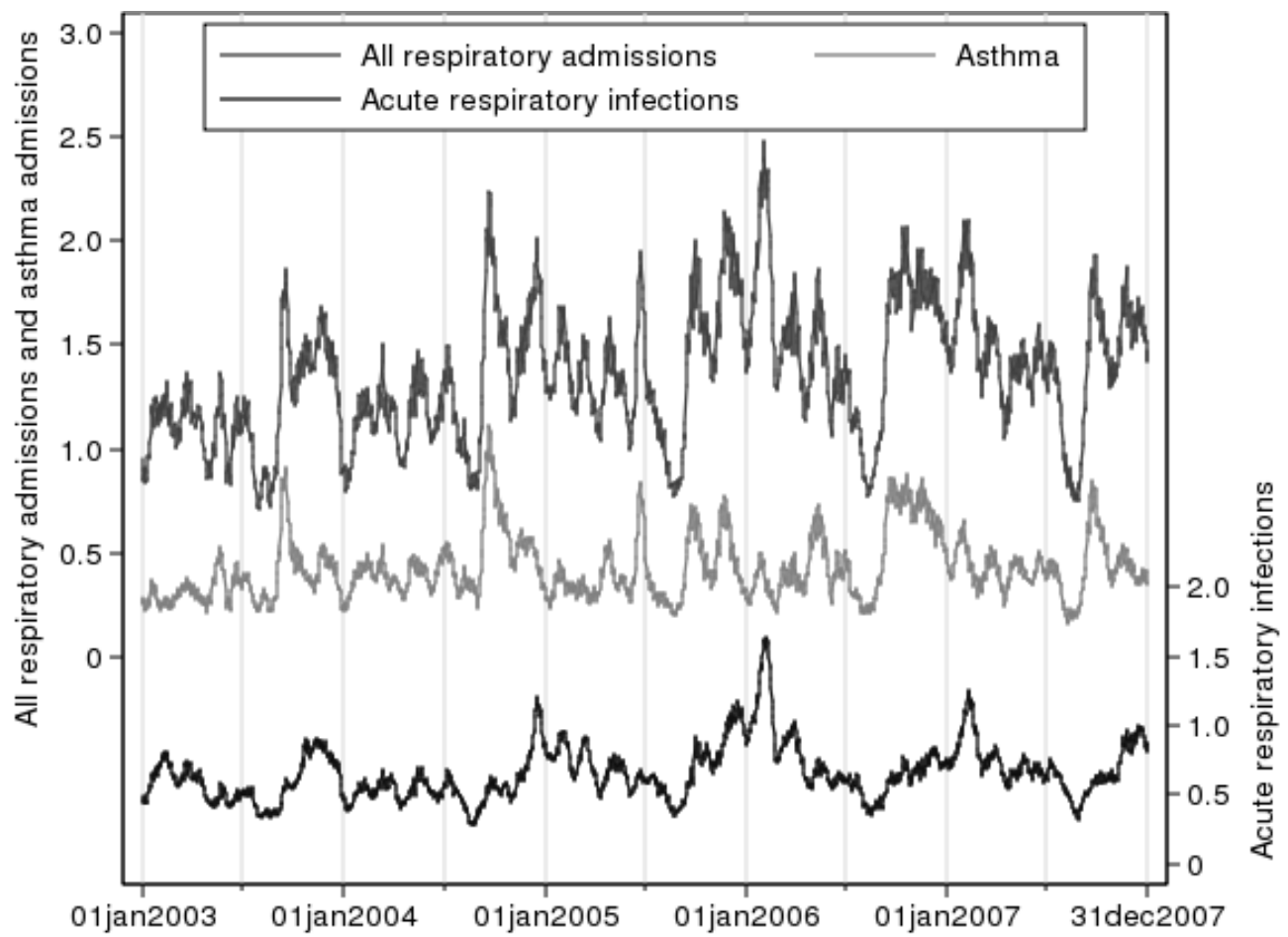

Figure A-1: Symmetric moving averages with a span of 10 days of daily means of hospital emergency admissions for all respiratory diseases and symptoms, asthma and acute respiratory infections in children aged 5 to 19 years

assign a measure of daily air pollutant concentrations to local authorities using the following procedure:

Firstly, I determine the local authorities' population-weighted centroids by calculating the mean of the population-weighted centroids of all the Middle Layer Super Output Areas in a local authority. Middle Layer Super Output Areas are geographic areas designed for reporting small area statistics, for which the Office for National Statistics provides populationweighted centroids (www.neighbourhood.statistics.gov.uk). Secondly, using the geographical coordinates of the centroids and the monitoring stations, I calculate the distances between a local authority's population-weighted centroid and all monitoring stations. Finally, I select all monitoring stations whose distance to the centroid is less than 5/10/15/20 km to calculate a weighted mean of the daily pollutant concentrations measured by these stations. The weight assigned to a monitor is the inverse of the distance between the centroid and the monitor, allowing stations closer to the centroid to have greater influence on the pollutant measure than stations farther away from the centroid. Table A-3 provides descriptive statistics on the size of the local authorities and the number of monitoring stations that contribute to the pollutant measures.

To assign meteorological measurements taken at the Met Office's observation stations to local authorities, I apply the same procedure, using a $20 \mathrm{~km}$ radius for rainfall measurements and a $30 \mathrm{~km}$ radius for temperature and wind speed measurements.

Figure A-2 plots symmetric moving averages with a span of 10 days of the daily means of $\mathrm{NO}_{2}$ and $\mathrm{O}_{3}$, showing a strong seasonal pattern. $\mathrm{NO}_{2}$ rises steeply between September and Christmas, then drops during the Christmas holidays, followed by a rebound in January and a gradual decrease until May, when concentrations drop below average levels until September. 
Table A-2: Sources of air pollution data

\begin{tabular}{ll}
\hline \hline Network & Website \\
\hline $\begin{array}{l}\text { Lutomatic Urban and Rural Network } \\
\text { Hertfordshire and Bedfordshire }\end{array}$ & http://uk-air.defra.gov.uk \\
Air Pollution Monitoring Network & www.londonair.org.uk \\
Kent and Medway Air & www.hertsbedsair.org.uk \\
Quality Monitoring Network & \\
Sussex Air Quality & www.kentair.org.uk \\
South Cambridgeshire District Council & www.sussex-air.net \\
Oxford Airwatch & www.oxford-airwatch.aeat.co.uk \\
Newham Council & www.newham.gov.uk/YourEnvironment/ \\
& AirPollution/MonitoringNewhamsAirQuality.htm \\
Air Quality Monitoring in Slough & http://sloughair.aeat.com/ \\
South Oxfordshire District Council & http://airquality.southoxon.gov.uk/ \\
& AirQuality/DataDownload.aspx \\
Leicester City Council & www.leicester.gov.uk/your-council-services/ep/ \\
& environmental-health-licensing/pollution/air-quality/ \\
\hline \hline
\end{tabular}

Table A-3: Descriptive statistics on construction of air pollution variables

\begin{tabular}{lccc}
\hline \hline & \multicolumn{2}{c}{ Number of monitors con- } \\
& $\begin{array}{c}\text { tributing to pollutant measure } \\
\mathrm{NO}_{2}\end{array}$ & $\mathrm{O}_{3}$ & $\begin{array}{c}\text { Area of local } \\
\text { authorities }\left(\mathrm{km}^{2}\right)\end{array}$ \\
\hline Mean & 4.6 & 3.3 & 132.9 \\
Minimum & 1 & 1 & 12 \\
$25^{\text {th }}$ percentile & 2 & 1 & 46 \\
Median & 3 & 2 & 87 \\
$75^{\text {th }}$ percentile & 6 & 4 & 157 \\
Maximum & 19 & 12 & 568 \\
\hline Observations & 148,210 & 148,210 & 89 \\
\hline \hline
\end{tabular}




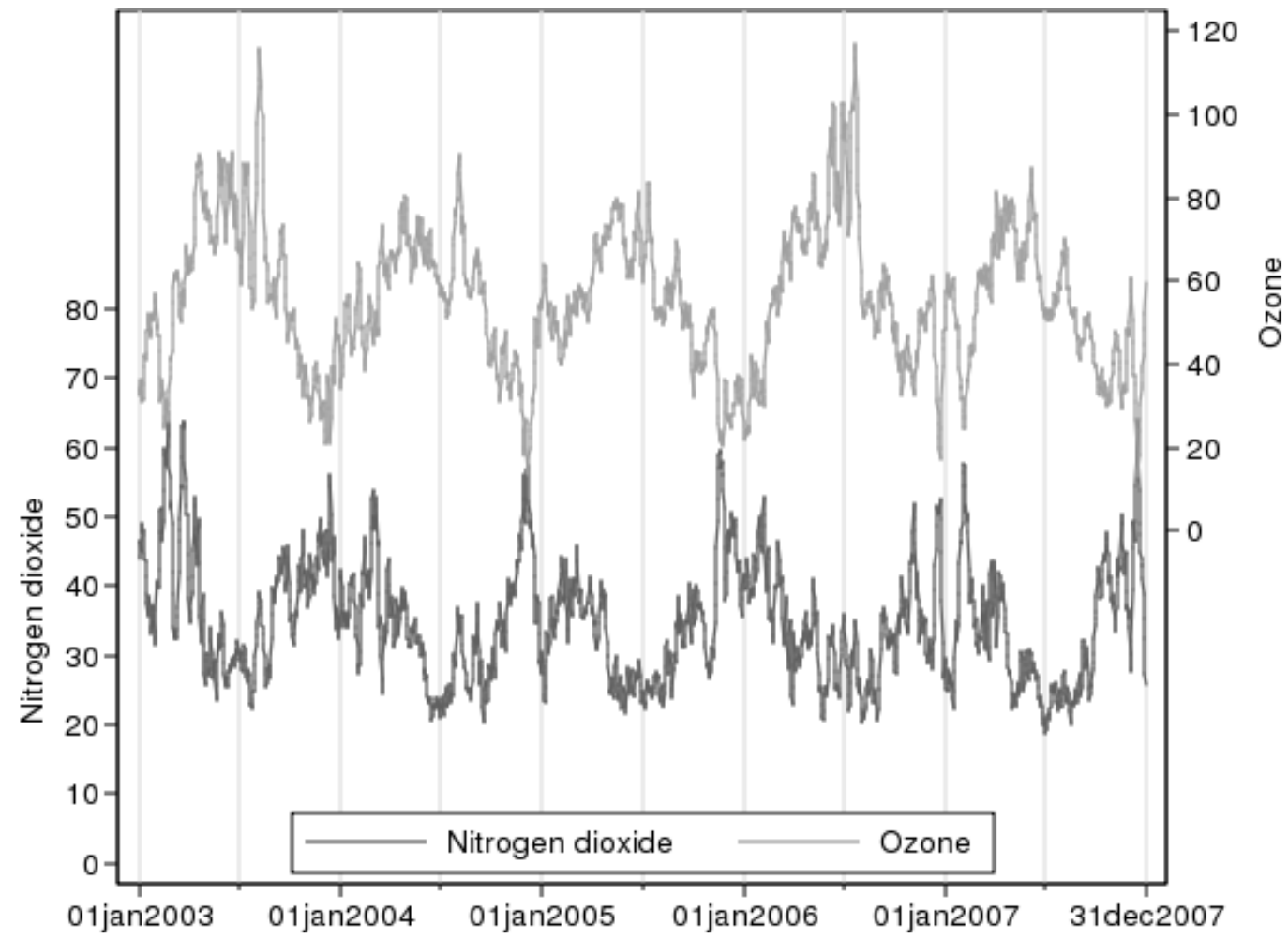

Figure A-2: Symmetric moving averages with a span of 10 days of daily means of nitrogen dioxide and ozone

The seasonal cycle of $\mathrm{O}_{3}$ is the opposite: levels are lowest during the winter months, start rising in March, peak during the summer months and then fall again in September.

The strong seasonal pattern might be reflected in other health related factors. Thus, it is important to account for seasonality in pollutants. Figure A-3 plots symmetric moving averages with a span of 10 days of daily means of the residuals of $\mathrm{NO}_{2}$ and $\mathrm{O}_{3}$ after adjusting for the meteorological variables $\boldsymbol{M}_{a, t-i}$, the dummy variable vector $\boldsymbol{X}_{t}$, local authority-yearquarter fixed effects and year-week effects. We see that the main specification successfully accounts for seasonality whilst leaving ample residual variation for obtaining precise estimates.

The air pollution forecast is produced for 9 Regions and 11 urban areas. Figure A-4 shows the Regions in relation to the local authorities in the estimation sample as well as the local authorities that are part of an urban area for pollution forecasting purposes. Figure A-5 plots monthly means of the air pollution warning dummy variable. Warnings are issued only rarely between October and February and more regularly between March and September.

To establish summer smog weather conditions, I analysed descriptive statistics for the weather variables during summer smog episodes that have been identified in the annual Air Pollution in the UK reports (see, for example, Department for Environment, Food and Rural Affairs (2006)). Additionally, I consulted descriptive statistics for the whole sample and the subsamples of observations for the summer months (June, July and August) with $\mathrm{O}_{3}$ values above the $90^{\text {th }}$ percentile. Summer smog episodes are characterised by daily maximum temperatures above $24^{\circ} \mathrm{C}$, daily minimum temperatures above $13{ }^{\circ} \mathrm{C}$ and daily rainfall amounts below $0.2 \mathrm{~mm}$.

Regarding winter smog episodes, the annual Air Pollution in the UK reports tend to focus on Bonfire night episodes, which are too specific for my purposes. Therefore, I analysed 


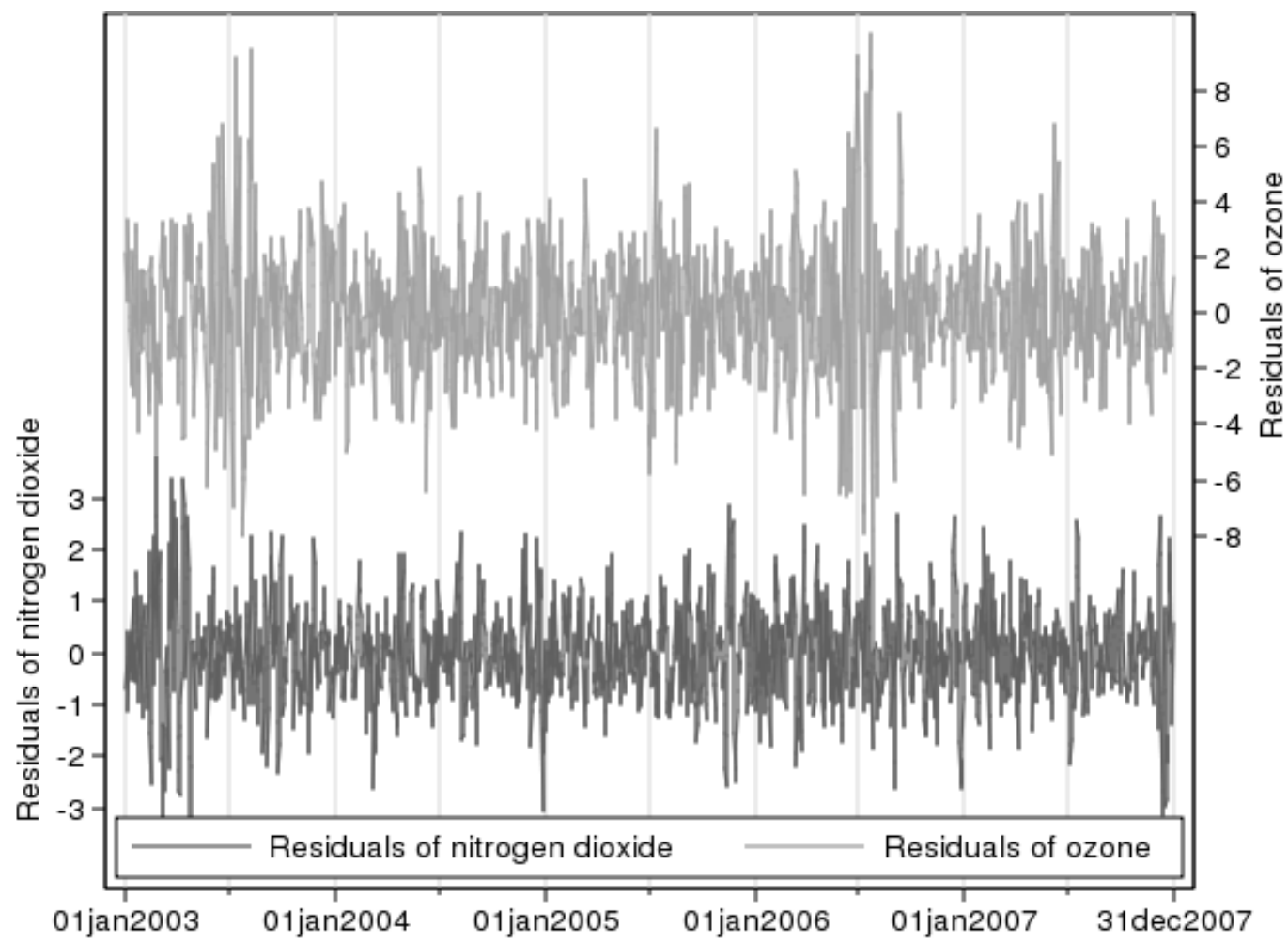

Figure A-3: Symmetric moving averages with a span of 10 days of daily means of residuals of nitrogen dioxide and ozone

Table A-4: Sample selection

\begin{tabular}{llll}
\hline \hline Sample & Observations & Local authorities & Clusters \\
\hline All English local authorities in 2003 to 2007 & 646,404 & 354 & 46 \\
Area $<600 \mathrm{~km}^{2}$ & 509,454 & 279 & 46 \\
Area $<600 \mathrm{~km}^{2} \&$ population $\geqslant 150,000$ & 209,735 & 100 & 29 \\
Estimation sample & 148,210 & 89 & 23 \\
\hline \hline
\end{tabular}

descriptive statistics for the subsample of observations in November and December. Observations with high $\mathrm{NO}_{2}$ levels, i.e. exceeding the $90^{\text {th }}$ percentile, are characterised by daily maximum temperatures below $10{ }^{\circ} \mathrm{C}$, daily minimum temperatures below $2{ }^{\circ} \mathrm{C}$, daily rainfall amounts below $0.1 \mathrm{~mm}$ and daily mean wind speeds below 5 knots.

There are a total of 5,900 local authority-day observation points with summer smog weather conditions and 4,935 local authority-day observations points with winter smog weather conditions. Of the 5,900 summer smog days 4,959 coincide with air pollution warning days and of the 4,935 winter smog days 1,680 coincide with air pollution warning days. Air pollution warnings are issued for a total of 43,727 local authority-day observations points. Hence, $15 \%$ of air pollution warning days coincide with weather conditions conducive to high levels of air pollution $(4,935+1,680=6,639 / 43,727=15 \%)$.

Table A-4 provides details on sample selection. 


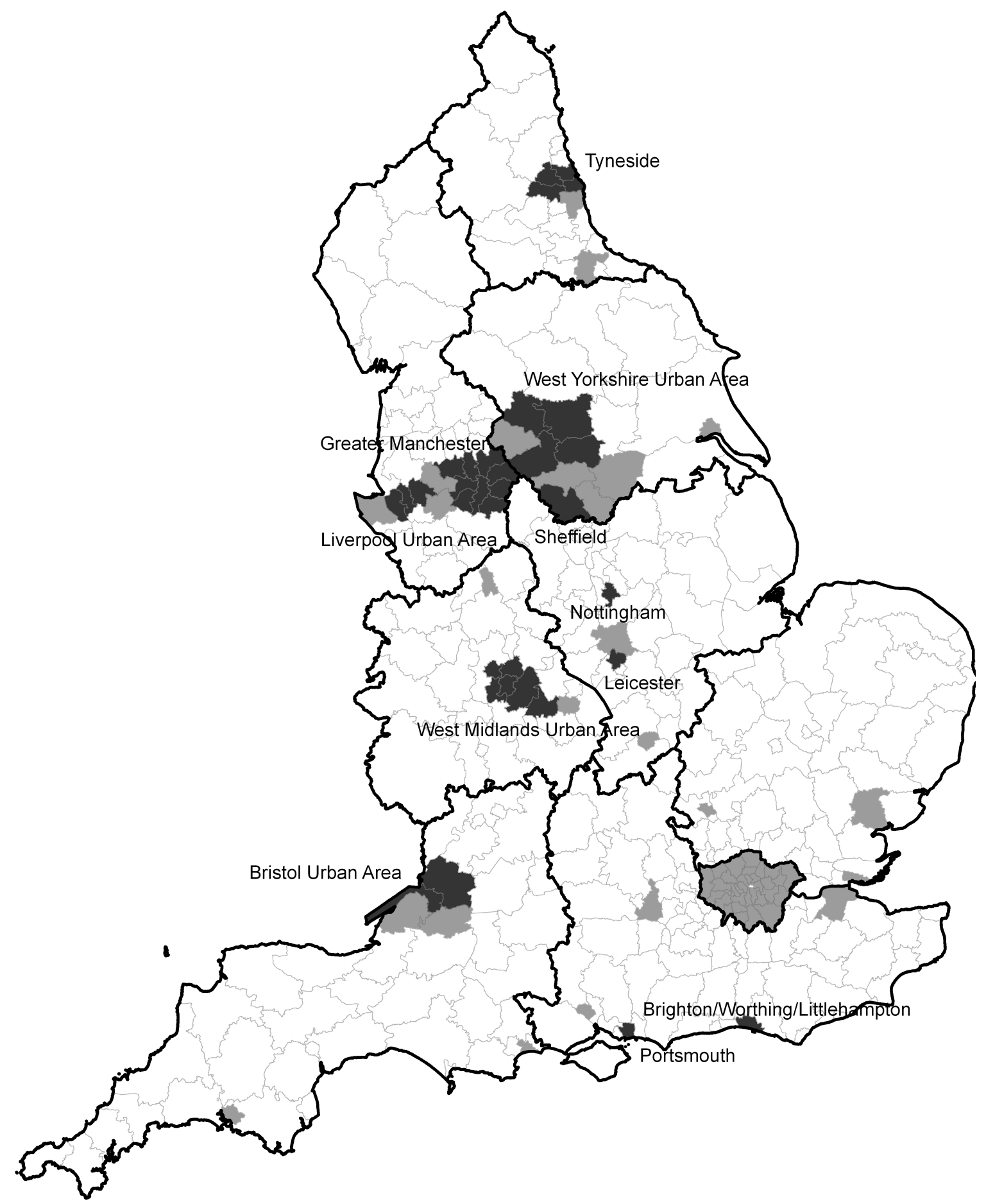

Figure A-4: Air pollution forecast zones and agglomerations: Bold boundary lines indicate zones (Regions). Shaded areas indicate local authorities in estimation sample, with darker shading indicating local authorities in forecast agglomerations (urban areas). 


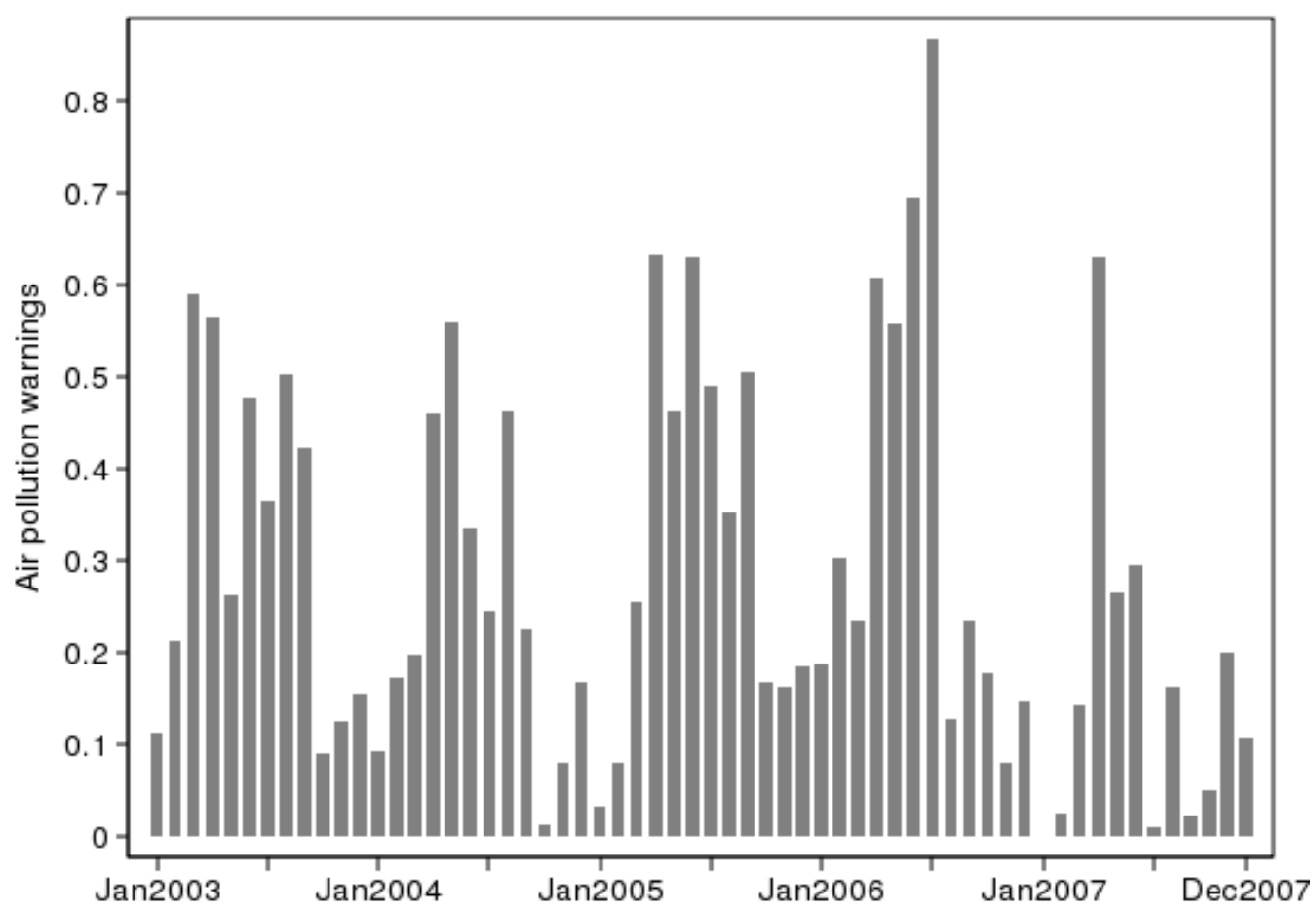

Figure A-5: Monthly means of air pollution warning dummy

\section{Appendix B Description of zoo data}

Bristol Zoo Gardens kindly provided their visitor data. To assign weather controls I apply the same inverse distance weighting procedure as for the air pollution data, using a $20 \mathrm{~km}$ radius for rainfall measurements and a $30 \mathrm{~km}$ radius for temperature and wind speed measurements. Descriptive statistics are in Table B-1.

\section{References}

Anderson, H. R., Bremner, S. A., Atkinson, R. W., Harrison, R. M. and Walters, S.: 2001, Particulate matter and daily mortality and hospital admissions in the West Midlands conurbation of the United Kingdom: associations with fine and coarse particle, black smoke and sulphate, Occupational Environmental Medicine 58, 504-510.

Atkinson, R. W., Bremner, S. A., Anderson, H. R., Strachan, D. P., Blan, J. M. and de Leon, A. P.: 1999, Short-term associations between emergency hospital admissions for respiratory and cardiovascular disease and outdoor air pollution in London, Archives of Environmental Health: An International Journal 54(6), 398-411.

Ballester, F., Tenias, J. M. and Perez-Hoyos, S.: 2001, Air pollution and emergency hospital admissions for cardiovascular diseases in Valencia, Spain, Journal of Epidemiology and Community Health $\mathbf{5 5}(1), 57-65$.

Bickerstaff, K. and Walker, G.: 1999, Clearing the smog? Public responses to air-quality information, Local Environment: The International Journal of Justice and Sustainability 4(3), 279-294.

Bresnahan, B. W., Dickie, M. and Gerking, S.: 1997, Averting behaviour and urban air pollution, Land Economics 73(3), 340-357. 
Table B-1: Descriptive statistics for zoo data

\begin{tabular}{lccrr}
\hline \hline & & & \multicolumn{2}{c}{ Percentiles } \\
Variable & Mean & Standard Deviation & $25^{\text {th }}$ & $75^{\text {th }}$ \\
\hline Number of visitors & & & & \\
$\quad$ Day visitors & 963 & 849 & 297 & 1512 \\
$\quad$ Members & 371 & 222 & 192 & 534 \\
Air pollution warning & 0.16 & & & \\
Maximum temperature $\left({ }^{\circ} \mathrm{C}\right)$ & 14.9 & 5.8 & 10.6 & 19.3 \\
Minimum temperature $\left({ }^{\circ} \mathrm{C}\right)$ & 7.5 & 5.0 & 3.9 & 11.5 \\
Rainfall $(\mathrm{mm})$ & 2.6 & 5.0 & 0.0 & 2.9 \\
Wind speed (knots) & 9.5 & 4.4 & 6.2 & 12.0 \\
Summer smog weather & 0.03 & & & \\
Winter smog weather & 0.02 & & & \\
\hline \hline
\end{tabular}

2,382 observations.

Burnett, R. T., Dales, R. E., Raizenne, M. E., Krewski, D., Summers, P. W., Roberts, G. R., RaadYoung, M., Dann, T. and Brook, J.: 1994, Effects of low ambient levels of ozone and sulfates on the frequency of respiratory admissions to Ontario hospitals, Environmental Research 65, 172194.

Chay, K., Dobkin, C. and Greenstone, M.: 2003, The Clean Air Act of 1970 and adult mortality, Journal of Risk and Uncertainty 27(3), 279 - 300.

Chay, K. Y. and Greenstone, M.: 2003, The impact of air pollution on infant mortality: Evidence from geographic variation in pollution shocks induced by a recession, The Quarterly Journal of Economics 118(3), 1121-1167.

Committee on the Medical Effects of Air Pollutants: 2000, The Health Effects of Air Pollutants: Advice from the Committee on the Medical Effects of Air Pollutants, Department of Health, London.

Committee on the Medical Effects of Air Pollutants: 2011, Review of the UK Air Quality Index, Health Protection Agency.

Coneus, K. and Spiess, C. K.: 2012, Pollution exposure and child health: Evidence for infants and toddlers in Germany, Journal of Health Economics 31(1), 180-196.

Currie, J. and Neidell, M.: 2005, Air pollution and infant health: What can we learn from California's recent experience?., Quarterly Journal of Economics 120(3), 1003 - 1030.

Currie, J., Neidell, M. and Schmieder, J. F.: 2009, Air pollution and infant health: Lessons from New Jersey, Journal of Health Economics 28(3), 688 - 703.

de Leon, A. P., Anderson, H. R., Bland, J. M., Strachan, D. P. and Bower, J.: 1996, Effects of air pollution on daily hospital admissions for respiratory disease in London between 1987-88 and 1991-92, Journal of Epidemiology and Community Health 33(Suppl 1), S63-S70.

Defra: 2007, Articulating public values in environmental policy development - Report on the Citizen's Jury on Air Quality.

URL: http: //uk-air. defra.gov. uk/reports/cat09/0711011358_report-summary. pdf

Department for Environment, Food and Rural Affairs: 2006, Air Pollution in the UK 2005, Department for Environment, Food and Rural Affairs.

Department for Environment, Food and Rural Affairs: 2007, The air quality strategy for England, Scotland, Wales and Northern Ireland - Volume 1, The Stationery Office, London.

Department for Environment, Food and Rural Affairs: 2010, Air Pollution in the UK 2009 - Edition $B$, Department for Environment, Food and Rural Affairs.

Department for Environment, Food and Rural Affairs: 2011, How are the forecasts produced? URL: http://uk-air.defra.gov.uk/forecasting/how-forecasts-are-produced

Department of Health: 1997, Handbook on Air Pollution and Health - Committee on the Medical Effects of Air Pollutants, The Stationery Office, London. 
Department of Health: 2004, National Tariff 2005-06, Department of Health.

Fusco, D., Forastiere, F., Michelozzi, P., Spadea, T., Ostro, B., Arca, M. and Perucci, C.: 2001, Air pollution and hospital admissions for respiratory conditions in Rome, Italy, European Respiratory Journal 17, 1143-1150.

Gern, J. E., Rosenthal, L. A., Sorkness, R. L. and Lemanske Jr., R. F.: 2005, Effects of viral respiratory infections on lung development and childhood asthma, Journal of Allergy and Clinical Immunology 115(4), $668-674$.

Grunert, K. G. and Wills, J. M.: 2007, A review of European research on consumer response to nutrition information on food labels, Journal of Public Health 15(5), 385-399.

Health Protection Agency: 2011, Surveillance of influenza and other respiratory viruses in the UK, 2010-2011 report, Health Protection Agency, London.

House of Commons Environmental Audit Committee: 2010, Air Quality - Fifth Report of Session 2009-10, The Stationery Office Limited, London.

Katsouyanni, K., Schwartz, J., Spix, C., Touloumi, G., Zmirou, D., Zanobetti, A., Wojtyniak, B., Vonk, J. M., Tobias, A., Ponka, A., Medina, S., Bacharova, L. and Anderson, H. R.: 1996, Short term effects of air pollution on health: a European approach using epidemiologic time series data: the APHEA protocol., Journal of Epidemiology and Community Health 50(Suppl 1), S12-S18.

Knittel, C. R., Miller, D. L. and Sanders, N. J.: 2011, Caution, drivers! Children present: Traffic, pollution, and infant health, Working Paper 17222, National Bureau of Economic Research.

Lleras-Muney, A.: 2010, The needs of the Army: using compulsory relocation in the military to estimate the effect of environmental pollutants on children's health, The Journal of Human Resources 45(3), 549-590.

Mansfield, C., Johnson, F. R. and Houtven, G. V.: 2006, The missing piece: Valuing averting behavior for children's ozone exposures, Resource and Energy Economics 28, 215-228.

McDermott, M., Srivastava, R. and Croskell, S.: 2006, Awareness and compliance with air pollution advisories: a comparison of parents of asthmatics with other parents, Journal of Asthma 43, 235239.

Moretti, E. and Neidell, M.: 2011, Pollution, health, and avoidance behavior, Journal of Human Resources 46(1), 154-175.

Neidell, M.: 2009, Information, avoidance behavior, and health, Journal of Human Resources $44(2), 450-478$.

Petroeschevsky, A., Simpson, R. W., Thalib, L. and Rutherford, S.: 2001, Associations between outdoor air pollution and hospital admissions in Brisbane, Australia, Archives of Environmental Health 56(1), 37-52.

Proud, D. and Chow, C.-W.: 2006, Role of viral infections in asthma and chronic obstructive pulmonary disease, Am. J. Respir. Cell Mol. Biol. 35(5), 513-518.

Schlenker, W. and Walker, W. R.: 2011, Airports, air pollution, and contemporaneous health, Working Paper 17684, National Bureau of Economic Research.

Skov, T., Cordtz, T., Jensen, L. K., Saugman, P., Schmidt, K. and Theilade, P.: 1991, Modifications of health behaviour in response to air pollution notifications in Copenhagen, Social Science and Medicine 33(5), 621-626.

Smallbone, K.: 2009, Air quality forecasting and its value as a preventive measure for sensitive people - Presentation at Investigation of Air Pollution Standing Conference.

URL: http: //www. iapsc. org. uk/document/1209_K_Smallbone. pdf

Sunyer, J., Spix, C., de Leon, A. P., Ponka, A., Barumandzadeh, T., Touloumi, G., Bacharova, L., Wojtyniak, B., Vonk, J., Bisanti, L., Schwartz, J. and Katsouyanni, K.: 1997, Urban air pollution and emergency admissions for asthma in four European cities: the APHEA Project, Thorax 52, 760-765.

World Health Organization: 2006, Air Quality Guidelines - Global Update 2005, WHO Regional Office for Europe, Copenhagen. 
World Health Organization - European Centre for Environment and Health: 2005, Effects of Air Pollution on Children's Health and Development - A Review of the Evidence, World Health Organization, Bonn.

Xu, Z., Etzel, R. A., Su, H., Huang, C., Guo, Y. and Tong, S.: 2012, Impact of ambient temperature on children's health: A systematic review, Environmental Research 117, 120-131. 


\section{Web appendix}

\section{Limit values for $\mathrm{NO}_{2}$ and $\mathrm{O}_{3}$}

For $\mathrm{NO}_{2}$, European legislation sets limit values for the hourly mean as well as the annual mean. The hourly mean must not exceed $200 \mu \mathrm{g} / \mathrm{m}^{3}$ more than 18 times a year. This limit value is based on evidence for the lowest $\mathrm{NO}_{2}$ level associated with acute adverse effects during temporary exposure (World Health Organization 2006). None of the $\mathrm{NO}_{2}$ values in the estimation sample exceeds $200 \mu \mathrm{g} / \mathrm{m}^{3}$, probably because I exclude kerbside and roadside monitoring stations, which tend to record the highest $\mathrm{NO}_{2}$ levels. The annual mean must not exceed $40 \mu \mathrm{g} / \mathrm{m}^{3}$, a target to be achieved by 2010. In the estimation sample, one-quarter of local authority-year observations points would have exceeded the limit value. However, the limit value for the annual mean is based on evidence for the lowest $\mathrm{NO}_{2}$ level associated with chronic and mostly irreversible adverse effects (World Health Organization 2006), so it is less relevant for this study of the relationship between $\mathrm{NO}_{2}$ and emergency admissions.

For $\mathrm{O}_{3}$, EU legislation sets a target value for the 8-hour maximum daily mean: it should not exceed $120 \mu \mathrm{g} / \mathrm{m}^{3}$ more than 25 times a year averaged over 3 years. Only $1.8 \%$ of observations exceed $120 \mu \mathrm{g} / \mathrm{m}^{3}$ and only two local authority-year observations points exceed the target of 25 days (Northampton in 2003 - 28 days with $\mathrm{O}_{3}$ levels higher than $120 \mu \mathrm{g} / \mathrm{m}^{3}$, Southend-on-Sea in 2006 - 27 days). The UK Air Quality Objective requires the 8-hour running mean of $\mathrm{O}_{3}$ not to exceed $100 \mu \mathrm{g} / \mathrm{m}^{3}$ more than 10 times a year. In the estimation sample, $4.3 \%$ of observations exceed $100 \mu \mathrm{g} / \mathrm{m}^{3}$. Ignoring the first 10 exceedances in each local authority in each year, the proportion of exceedances drops to $2 \%$ of observations.

\section{Robustness test: Replace local authority-year-quarter fixed effects with lo- cal authority-year-month fixed effects}

The main specification includes local authority-year-quarter fixed effects as well as year-week effects. The local authority-year-quarter fixed effects absorb unobserved differences between local authorities, allowing these differences to evolve at a quarterly rate. The year-week effects absorb seasonal cycles as well as influenza epidemics, assuming these influences on emergency admissions vary at a weekly rate. The table below explores a specification that replaces local authority-year-quarter fixed effects with local authority-year-month fixed effects, allowing the unobserved differences between local authorities to change from month to month.

The qualitative results are unchanged: $\mathrm{NO}_{2}$ and $\mathrm{O}_{3}$ are positively associated with all three admission rates while avoidance behaviour is evident only for asthma admissions. Comparing results for all respiratory admissions to the main estimates in Column 1 of Table 2, the pollutant coefficients increase, while the coefficient on the air pollution warning dummy drops. The size of these changes ranges from 10 to $20 \%$. The subset of asthma admissions drives the increase in the pollutant coefficients, because compared to the results in Column 3 of Table 3 the pollutant coefficients for asthma admissions increase by $60 \%$. The coefficient on the air 
pollution warning dummy drops by $20 \%$ but is still statistically significant at the $5 \%$ level. For acute respiratory infections the pollutant coefficients drop by $20 \%$, presumably because of the seasonality of respiratory infections, which is likely to result in the local authority-yearmonth fixed effects and national year-week fixed effects absorbing most of the variation. As the qualitative results are robust to local authority-year-month effects, the risk of overcontrolling makes local authority-year-quarter effects the preferred specification.

Table 2: Robustness of the association between air pollutants and hospital emergency admissions to replacing local authority-year-quarter fixed effects with local authority-year-month fixed effects

\begin{tabular}{lccc}
\hline \hline & $\begin{array}{c}\text { All respiratory } \\
\text { admissions }\end{array}$ & $\begin{array}{c}\text { Acute respiratory } \\
\text { infections }\end{array}$ & Asthma \\
\hline $\mathrm{NO}_{2} / 10$ & $0.039^{* *}$ & 0.007 & $0.021^{* *}$ \\
& $(0.009)$ & $(0.006)$ & $(0.005)$ \\
$\mathrm{O}_{3} / 10$ & {$[0.100]$} & {$[0.039]$} & {$[0.172]$} \\
& $0.032^{* *}$ & 0.009 & $0.010^{* *}$ \\
Summer smog weather & $(0.009)$ & $(0.005)$ & $(0.004)$ \\
& {$[0.131]$} & {$[0.074]$} & {$[0.136]$} \\
& -0.052 & 0.005 & -0.024 \\
Winter smog weather & $(0.059)$ & $(0.024)$ & $(0.038)$ \\
& {$[-3.800]$} & {$[0.710]$} & {$[-5.602]$} \\
& -0.011 & 0.046 & -0.017 \\
Air pollution warning & $(0.051)$ & $(0.039)$ & $(0.031)$ \\
& {$[-0.807]$} & {$[6.918]$} & {$[-3.876]$} \\
& $(0.031)$ & 0.013 & $-0.027^{*}$ \\
& {$[-1.931]$} & {$[0.021)$} & $(0.010)$ \\
\hline \hline
\end{tabular}

Robust standard errors in (round brackets), clustered at county level. Numbers in [square brackets] are elasticities at the mean for $\mathrm{NO}_{2}, \mathrm{O}_{3}, \mathrm{PM}_{10}, \mathrm{CO}$ and $\mathrm{SO}_{2}$ and percent change in admission rate (evaluated at the mean) for discrete change of Air pollution warning, Summer smog weather and Winter smog weather dummy from 0 to 1 . Coefficients are sum of coefficients on contemporaneous value and four lags of regressors. All regressions include local authorityyear-month fixed effects, year-week fixed effects as well as dummies for day of week, public holidays in winter, public holidays in summer, bank holiday weekends, school holidays and school holiday weekends and contemporaneous value and four lags of maximum and minimum temperature, total amount of rainfall and mean wind speed. Observations weighted by size of local authority population. 148,210 observations in 89 local authorities with 23 county clusters in all regressions. ${ }^{*}$ Significant at $5 \%,{ }^{*}$ significant at $1 \%$ 


\section{Detailed discussion of interaction effects}

The protective effect of an air pollution warning potentially depends on the level of pollution. Alternatively, an air pollution warning might modify the impact of $\mathrm{NO}_{2}$ and $\mathrm{O}_{3}$ on hospital admissions. To investigate potential interaction effects, Table 7 reports results from regressions that include interaction terms between the pollutant concentrations and the air pollution warning dummy.

For all respiratory admissions and asthma admissions, the coefficients on the interaction terms are positive, while the coefficient on the warning dummy is negative, which suggests that the protective effect of an air pollution warning decreases as $\mathrm{NO}_{2}$ or $\mathrm{O}_{3}$ increase. The flip side of this result is that an air pollution warning increases the marginal effects of $\mathrm{NO}_{2}$ and $\mathrm{O}_{3}$ on hospital emergency admissions. As this result might be counterintuitive, the table below presents predicted rates for all respiratory admissions and asthma admissions for varying values of $\mathrm{NO}_{2}$ and $\mathrm{O}_{3}$, comparing admission rates for warning days and non-warning days. Column 1 shows that on non-warning days an increase in $\mathrm{NO}_{2}$ or $\mathrm{O}_{3}$ increases the all respiratory admission rate relatively little. Column 2 shows a stronger increase in the admission rate per increase in $\mathrm{NO}_{2}$ or $\mathrm{O}_{3}$ on warning days. However, for each combination of $\mathrm{NO}_{2}$ and $\mathrm{O}_{3}$ levels, the admission rate is lower on warning days. The only exceptions are the combinations $\mathrm{NO}_{2}$ at the $50^{\text {th }}$ or $75^{\text {th }}$ percentile and $\mathrm{O}_{3}$ at the $75^{\text {th }}$ percentile, but as $\mathrm{NO}_{2}$ and $\mathrm{O}_{3}$ are negatively correlated these combinations are rare and akin to an out-of-sample prediction.

Predicted hospital emergency admission rates from model with interaction terms

\begin{tabular}{lcccc}
\hline \hline $\begin{array}{l}\text { Values of pollutants } \\
\text { (in percentiles) }\end{array}$ & \multicolumn{2}{c}{ All respiratory admissions } & \multicolumn{2}{c}{ Asthma } \\
\hline $\mathrm{NO}_{2}=25^{\text {th }}, \mathrm{O}_{3}=25^{\text {th }}$ & Warning $=0$ & Warning $=1$ & Warning $=0$ & Warning $=1$ \\
$\mathrm{NO}_{2}=25^{\text {th }}, \mathrm{O}_{3}=50^{\text {th }}$ & 1.55 & 1.47 & .59 & .51 \\
$\mathrm{NO}_{2}=25^{\text {th }}, \mathrm{O}_{3}=75^{\text {th }}$ & 1.59 & 1.53 & .58 & .53 \\
\hline $\mathrm{NO}_{2}=50^{\text {th }}, \mathrm{O}_{3}=25^{\text {th }}$ & 1.58 & 1.58 & .58 & .54 \\
$\mathrm{NO}_{2}=50^{\text {th }}, \mathrm{O}_{3}=50^{\text {th }}$ & 1.6 & 1.56 & .59 & .53 \\
$\mathrm{NO}_{2}=50^{\text {th }}, \mathrm{O}_{3}=75^{\text {th }}$ & 1.61 & 1.62 & .59 & .55 \\
\hline $\mathrm{NO}_{2}=75^{\text {th }}, \mathrm{O}_{3}=25^{\text {th }}$ & 1.61 & 1.55 & .6 & .56 \\
$\mathrm{NO}_{2}=75^{\text {th }}, \mathrm{O}_{3}=50^{\text {th }}$ & 1.63 & 1.61 & .59 & .56 \\
$\mathrm{NO}_{2}=75^{\text {th }}, \mathrm{O}_{3}=75^{\text {th }}$ & 1.65 & 1.67 & .59 & .59 \\
\hline \hline
\end{tabular}

Predictions computed with continuous weather variables held constant at their means, week set to first week of January 2003, day of week set to Monday and remaining dummy variables set to zero. $\mathrm{NO}_{2}$ at $25^{\text {th }}$ percentile $=22.05 \mu \mathrm{g} / \mathrm{m}^{3}, 50^{\text {th }}$ percentile $=32.04 \mu \mathrm{g} / \mathrm{m}^{3}$ and $75^{\text {th }}$ percentile $=44.43 \mu \mathrm{g} / \mathrm{m}^{3} . \mathrm{O}_{3}$ at $25^{\text {th }}$ percentile $=40.00 \mu \mathrm{g} / \mathrm{m}^{3}, 50^{\text {th }}$ percentile $=55.55 \mu \mathrm{g} / \mathrm{m}^{3}$ and $75^{\text {th }}$ percentile $=69.83 \mu \mathrm{g} / \mathrm{m}^{3}$.

Columns 1 and 2 also show that as $\mathrm{NO}_{2}$ and $\mathrm{O}_{3}$ increase, air pollution warnings become less effective in reducing emergency admissions, since the difference between the admission rate when Warning $=0$ and the admission rate when Warning $=1$ decreases as $\mathrm{NO}_{2}$ or

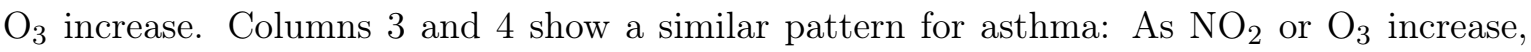


the difference between the predicted admission rate for Warning $=0$ and the prediction for Warning $=1$ decreases. As for all respiratory admissions, the marginal effects of $\mathrm{NO}_{2}$ and $\mathrm{O}_{3}$ are stronger on warning days, though the asthma admission rate does not seem to change at all on non-warning days. The reason might be that according to Figure A-5 in Appendix A periods with few air pollution warnings, i.e. Warning $=0$, tend be in the autumn and winter months, during which according to Figure A-1 there is relatively little variation in asthma admission rates, making it difficult to identify the effects of $\mathrm{NO}_{2}$ and $\mathrm{O}_{3}$ on asthma admissions for Warning $=0$. 
Table 3: Estimates of the association between air pollutants and hospital emergency admissions in children aged 5 to 19 years with coefficients on contemporaneous value and lags of regressors reported separately

\begin{tabular}{|c|c|c|c|}
\hline & $\begin{array}{l}\text { All respiratory } \\
\text { admissions }\end{array}$ & $\begin{array}{c}\text { Acute respiratory } \\
\text { infections }\end{array}$ & Asthma \\
\hline $\mathrm{NO}_{2 t}$ & $\begin{array}{c}0.001 \\
(0.007)\end{array}$ & $\begin{array}{c}0.004 \\
(0.005)\end{array}$ & $\begin{array}{r}-0.004 \\
(0.004)\end{array}$ \\
\hline $\mathrm{NO}_{2 t-1}$ & $\begin{array}{c}0.008 \\
(0.010)\end{array}$ & $\begin{array}{r}-0.000 \\
(0.007)\end{array}$ & $\begin{array}{c}0.003 \\
(0.004)\end{array}$ \\
\hline $\mathrm{NO}_{2 t-2}$ & $\begin{array}{c}0.010 \\
(0.006)\end{array}$ & $\begin{array}{c}0.001 \\
(0.005)\end{array}$ & $\begin{array}{r}0.008^{*} \\
(0.003)\end{array}$ \\
\hline $\mathrm{NO}_{2 t-3}$ & $\begin{array}{c}0.003 \\
(0.009)\end{array}$ & $\begin{array}{c}0.000 \\
(0.007)\end{array}$ & $\begin{array}{r}-0.002 \\
(0.003)\end{array}$ \\
\hline $\mathrm{NO}_{2 t-4}$ & $\begin{array}{r}0.014^{*} \\
(0.005)\end{array}$ & $\begin{array}{c}0.004 \\
(0.003)\end{array}$ & $\begin{array}{r}0.007^{*} \\
(0.003)\end{array}$ \\
\hline $\mathrm{O}_{3 t}$ & $\begin{array}{r}-0.003 \\
(0.006)\end{array}$ & $\begin{array}{c}0.001 \\
(0.003)\end{array}$ & $\begin{array}{r}-0.004^{*} \\
(0.002)\end{array}$ \\
\hline $\mathrm{O}_{3 t-1}$ & $\begin{array}{c}0.010^{*} \\
(0.004)\end{array}$ & $\begin{array}{c}0.007^{* *} \\
(0.002)\end{array}$ & $\begin{array}{c}0.003 \\
(0.002)\end{array}$ \\
\hline $\mathrm{O}_{3 t-2}$ & $\begin{array}{l}0.011^{* *} \\
(0.003)\end{array}$ & $\begin{array}{c}0.002 \\
(0.004)\end{array}$ & $\begin{array}{r}0.006^{*} \\
(0.002)\end{array}$ \\
\hline $\mathrm{O}_{3 t-3}$ & $\begin{array}{r}0.009^{*} \\
(0.003)\end{array}$ & $\begin{array}{c}0.003 \\
(0.003)\end{array}$ & $\begin{array}{r}0.004^{*} \\
(0.002)\end{array}$ \\
\hline $\mathrm{O}_{3 t-4}$ & $\begin{array}{c}-0.002 \\
(0.005)\end{array}$ & $\begin{array}{r}-0.002 \\
(0.003)\end{array}$ & $\begin{array}{c}-0.003 \\
(0.002)\end{array}$ \\
\hline Air pollution warning ${ }_{t}$ & $\begin{array}{r}-0.015 \\
(0.017)\end{array}$ & $\begin{array}{c}0.006 \\
(0.016)\end{array}$ & $\begin{array}{r}-0.009 \\
(0.005)\end{array}$ \\
\hline Air pollution warning $g_{t-1}$ & $\begin{array}{c}0.005 \\
(0.016)\end{array}$ & $\begin{array}{c}0.005 \\
(0.012)\end{array}$ & $\begin{array}{r}-0.005 \\
(0.006)\end{array}$ \\
\hline Air pollution warning $g_{t-2}$ & $\begin{array}{r}-0.021 \\
(0.019)\end{array}$ & $\begin{array}{r}-0.010 \\
(0.013)\end{array}$ & $\begin{array}{r}-0.009 \\
(0.005)\end{array}$ \\
\hline Air pollution warning $t-3$ & $\begin{array}{r}-0.001 \\
(0.015)\end{array}$ & $\begin{array}{c}0.017 \\
(0.010)\end{array}$ & $\begin{array}{r}-0.014 \\
(0.010)\end{array}$ \\
\hline Air pollution warning $t_{t-4}$ & $\begin{array}{c}0.002 \\
(0.016)\end{array}$ & $\begin{array}{r}-0.006 \\
(0.010)\end{array}$ & $\begin{array}{c}0.002 \\
(0.004)\end{array}$ \\
\hline
\end{tabular}

Robust standard errors in (round brackets), clustered at county level. $\mathrm{NO}_{2}$ and $\mathrm{O}_{3}$ divided by 10. All regressions include local authority-year-quarter fixed effects and year-week fixed effects as well as dummies for day of week, public holidays in winter, public holidays in summer, bank holiday weekends, school holidays and school holiday weekends and contemporaneous value and four lags of maximum and minimum temperature, total amount of rainfall, mean wind speed, summer smog weather dummy and winter smog weather dummy. Observations weighted by size of local authority population. 148,210 observations in 89 local authorities with 23 county clusters in all regressions. ${ }^{*}$ Significant at $5 \%, * *$ significant at $1 \%$ 
Descriptive statistics of estimation sample for multi-pollutant model in Table 5

\begin{tabular}{lcccc}
\hline \hline & \multicolumn{4}{c}{ Standard deviation } \\
Variable & Mean & Overall & Between & Within \\
\hline Admissions for respiratory diseases & & & & \\
and symptoms (per 100,000 population) & 1.35 & 1.8 & 0.4 & 1.7 \\
Nitrogen dioxide $\left(\mu \mathrm{g} / \mathrm{m}^{3}\right)$ & 35.4 & 16.6 & 7.3 & 14.9 \\
Ozone $\left(\mu \mathrm{g} / \mathrm{m}^{3}\right)$ & 55.2 & 25.1 & 5.6 & 24.5 \\
Particulate matter $\left(\mu \mathrm{g} / \mathrm{m}^{3}\right)$ & 24.9 & 12.4 & 3.3 & 11.9 \\
Carbon monoxide $\left(\mathrm{mg} / \mathrm{m}^{3}\right)$ & 0.52 & 0.4 & 0.1 & 0.4 \\
Sulphur dioxide $\left(\mu \mathrm{g} / \mathrm{m}^{3}\right)$ & 5.72 & 4.5 & 2.0 & 4.1 \\
Air pollution warning & 0.29 & 0.5 & 0.1 & 0.4 \\
Maximum temperature $\left({ }^{\circ} \mathrm{C}\right)$ & 14.7 & 6.2 & 0.8 & 6.2 \\
Minimum temperature $\left({ }^{\circ} \mathrm{C}\right)$ & 7.3 & 5.1 & 0.6 & 5.0 \\
Rainfall $(\mathrm{mm})$ & 2.0 & 3.9 & 0.5 & 3.9 \\
Wind speed (knots) & 7.7 & 3.8 & 1.3 & 3.6 \\
Summer smog weather & 0.04 & 0.2 & 0.0 & 0.2 \\
Winter smog weather & 0.03 & 0.2 & 0.2 & 0.2 \\
Population, age 5 to 19 & 61,721 & 41,301 & & \\
Population, all ages (for weighting) & 322,252 & 192,888 & & \\
\hline \hline 117,355 observations. Observations weighted by size of local authority population.
\end{tabular}

